\title{
Article \\ Molecular Distillation of Lavender Supercritical Extracts: Physicochemical and Antimicrobial Characterization of Feedstocks and Assessment of Distillates Enriched with Oxygenated Fragrance Components
}

\author{
Agnieszka Dębczak ${ }^{1, *}$, Katarzyna Tyśkiewicz ${ }^{1}$ (D), Zygmunt Fekner ${ }^{1}$, Piotr Kamiński ${ }^{1}$ (D), Grzegorz Florkowski ${ }^{1}$, \\ Marcin Konkol ${ }^{1}$, Edward Rój ${ }^{1}$, Agnieszka Grzegorczyk ${ }^{2}$ iD and Anna Malm ${ }^{2}$ (D)
}

1 Łukasiewicz Research Network-New Chemical Syntheses Institute, Al. Tysiąclecia Państwa Polskiego 13A 24-110 Puławy, Poland; katarzyna.tyskiewicz@ins.lukasiewicz.gov.pl (K.T.); zygmunt.fekner@ins.lukasiewicz.gov.pl (Z.F.); piotr.kaminski@ins.lukasiewicz.gov.pl (P.K.); grzegorz.florkowski@ins.lukasiewicz.gov.pl (G.F.); marcin.konkol@ins.lukasiewicz.gov.pl (M.K.); edward.roj@ins.lukasiewicz.gov.pl (E.R.)

2 Chair and Department of Pharmaceutical Microbiology, Medical University of Lublin, 1 Chodźki Str., 20-093 Lublin, Poland; agnieszka.grzegorczyk@umlub.pl (A.G.); anna.malm@umlub.pl (A.M.)

* Correspondence: agnieszka.debczak@ins.lukasiewicz.gov.pl; Tel.: +48-814704905

check for updates

Citation: Dębczak, A.; Tyśkiewicz, K. Fekner, Z.; Kamiński, P.; Florkowski, G.; Konkol, M.; Rój, E.; Grzegorczyk, A.; Malm, A. Molecular Distillation of Lavender Supercritical Extracts: Physicochemical and Antimicrobial Characterization of Feedstocks and Assessment of Distillates Enriched with Oxygenated Fragrance Components. Molecules 2022, 27, 1470. https://doi.org/10.3390/ molecules27051470

Academic Editors: Luisella Verotta and Stefania Marzorati

Received: 2 February 2022

Accepted: 20 February 2022

Published: 22 February 2022

Publisher's Note: MDPI stays neutral with regard to jurisdictional claims in published maps and institutional affiliations.

Copyright: (C) 2022 by the authors. Licensee MDPI, Basel, Switzerland. This article is an open access article distributed under the terms and conditions of the Creative Commons Attribution (CC BY) license (https:// creativecommons.org/licenses/by/ $4.0 /)$
Abstract: Lavandula angustifolia is one of the most widely cultivated non-food crops used in the production of essential oil; it is used in perfumery, aromatherapy, pharmaceutical preparations, and food ingredients. In this study, supercritical fluid extraction (SFE) and molecular distillation (MD) were combined, primarily to enrich $\mathrm{scCO}_{2}$ extracts with lavender oxygenated monoterpenes, avoiding thermal degradation, hydrolysis, and solvent contamination, and maintaining the natural characteristics of the obtained oils. Molecular distillation was developed for the first time for the extraction of crucial lavender fragrance ingredients, i.e., from two $\mathrm{scCO}_{2}$ extracts obtained from dry flower stems of lavender cultivated in Poland and Bulgaria. The best results for high-quality distillates were obtained at $85^{\circ} \mathrm{C}$ (EVT) and confirmed that linalyl acetate content increased from $51.54 \mathrm{mg} / \mathrm{g}$ (initial Bulgarian lavender extract, L-Bg-E) and $89.53 \mathrm{mg} / \mathrm{g}$ (initial Polish lavender extract, $\mathrm{L}-\mathrm{Pl}-\mathrm{E})$ to 118.41 and $185.42 \mathrm{mg} / \mathrm{g}$, respectively, corresponding to increases of 2.3 and 2.1 times in both distillate streams, respectively. The distillates, light oils, and extracts from lavender were also evaluated for their antimicrobial properties by determining the minimum inhibitory concentration (MIC) by the broth microdilution method. Generally, Gram-positive bacteria and Candida spp. were more sensitive to all distilled fractions and extracts than Escherichia coli (Gram-negative bacteria).

Keywords: antibacterial and antifungal activity; coumarins; lavender; molecular distillation; natural wax ingredients; oxygenated terpenes; pilot-scale SFE

\section{Introduction}

Lavender (Lavandula angustifolia Mill.), recognizable as medicinal lavender, is a known source of precious fragrance molecules, with predominating linalyl acetate and linalool, which belong to the group of oxygenated monoterpenes, representing $73 \%$ of essential oil compositions [1]. Both compounds are responsible for a wide range of pharmacological effects, such as anti-inflammatory, antifungal, antibacterial, anti-viral, antioxidant, cicatrizant properties, and anxiety-reducing [2-6]. Moreover, the stress-relieving and sleep-promoting benefits of lavender oil are therapeutically used in aromatherapy and massages [5,7]. The benefits of essential oils from the Lavandula include their strong antiseptic properties, which make this specialty oil applicable, directly to pharmaceuticals and cosmetics, most of which are related to skincare products [8]. The latest studies on the potential of L. angustifolia 
essential oil revealed its beneficial impact on melanogenesis and its inhibition of tyrosinase, which can be attributed to one of the lavender oxygenated monoterpenes, namely terpinen-4-ol [9].

Due to a high demand for linalyl and lavandulyl acetates, which, together with linalool and lavandulol, are of special interest for cosmetic and perfumery applications, the attention is placed on the effective purification technology of these valuable compounds. The conventional/fundamental - and often used extraction methods of lavender essential oils-involve steam distillation and hydrodistillation as its variants. However, there are several crucial aspects regarding these two extraction methods (steam and hydrodistillation), including a proper time to release valuable compounds without the influence on their structures [10]. The effect of prolonged steam contact is reflected in product composition, especially caused by the hydrolysis of linalyl acetate to linalool [11]. The use of modern extraction methods, for instance, with carbon dioxide in a supercritical state (SFE), offers the extraction of biologically active compounds without a negative impact on their properties and, more importantly, on the environment [12]. Since the most precious components of Lavandula angustifolia Mill. are oxygenated compounds, including derivatives of monoterpenes, i.e., esters and alcohols (linalool, lavandulol, linalyl acetate, lavandulyl acetate), sesquiterpenes, and lactones (coumarins), SFE has been utilized for the extraction of Lavandula angustifolia of different origins (Bulgarian and Polish). According to Jerkovic et al. [13], the highest total extraction yield $(7.28 \%)$ and highest relative amount of oxygenated monoterpenes, i.e., linalool and linalyl acetate from L. angustifolia, was obtained at $30 \mathrm{MPa}$ and $50{ }^{\circ} \mathrm{C}$. Nadalin et al. [14] highlighted that by increasing the $\mathrm{scCO}_{2}$ pressure from 10 to $30 \mathrm{Mpa}$, with a constant temperature $\left(40^{\circ} \mathrm{C}\right)$, the extraction yield also increased (from 5.16 to $7.08 \mathrm{~g} / 100 \mathrm{~g}$ D.W. (dry weight)). Moreover, extraction is the first step toward separating bioactive compounds and, thus, may be considered as a pre-stage for further separation [15].

The vacuum distillation and SFE fractionations were first applied for the production of high quality oxygenated compounds (linalool and linalyl acetate) from cold-pressed bergamot oil, using the former technique mostly for the removal of limonene [16]. The relatively low recovery of oxygenated compounds was obtained with non-continuous batch distillations on an industrial scale, as waxes, pigments, and oxygenated fragrance molecules were not efficiently separated in the system due to high viscosity and, thus, remained in residual vessel [16]. The higher effectiveness may be achieved with the use of the molecular distillation than with conventional methods [17]. The combination of a very short residence time (1-10 s) of a separated product within a distillation unit, a continuous mass transfer of evaporated molecules traveling in a free flow regime through the distillation gap (10-50 $\mathrm{mm}$ ) onto the surface of the condenser, and high vacuum levels in the $0.1333-133.3$ Pa range $[18,19]$, were successfully applied for the separation and purification of thermally unstable products preserving their functional properties. The influence of molecular distillation operating parameters, primarily the evaporator temperature (EVT) and feed flow rate (FF), was thoroughly studied in order to increase the concentration of precious scent ingredients, i.e., citral [20], geranial [21], linalool [22], and sesquiterpenoids, i.e., patchouli alcohol [23], which all belong to oxygenated compounds. The major ingredient of the citrus oil light terpenic fraction recovered in the distillate was D-limonene [21,22]. Hydro-distilled essential oils derived from rosemary [24], oregano [25], and rose [26], mostly known for their antimicrobial and antioxidant activities, were subjected to molecular distillation. The obtained fractions showed higher antioxidant and antimicrobial activities relative to their original essential oils; hence, they may be used as natural additives for food preservation [25] or plant-based pharmaceuticals and healthcare products [26]. Some challenging applications of molecular distillation involve further purification and fractionation of supercritical fluid extracts to prepare standardized typical volatile components fractions from Curcuma species [15] or separate essential oils and wax-like residues from Artemisia anпиа L. $\mathrm{scCO}_{2}$ extracts, depending on the optimized extraction parameters [27]. Pilot scale supercritical $\mathrm{CO}_{2}$ extraction coupled with molecular 
distillation (SFE-MD) was recently applied for the separation of essential oils from Artemisia argyi Lévl. Et Vant [28]. Currently, molecular distillation is considered advantageous, in regard to purifying high molecular weight compounds without thermally degrading the products, such as rice bran wax unsaponifiable components [29]. One of the newest demanding applications of MD involves the fractionation of polyethylene wax, which, performed on a pilot scale, is reported to be a promising solution for recycling and recovery of high value-added products with narrower carbon numbers [30].

In this study, the supercritical fluid extraction and molecular distillation were combined primarily to enrich $\mathrm{scCO}_{2}$ extracts with lavender oxygenated monoterpenes, avoiding thermal degradation or hydrolysis and solvent contamination, and maintaining the natural characteristics of the obtained oils. Molecular distillation was developed for the first time for the extraction of crucial lavender fragrance ingredients, i.e., from two $\mathrm{scCO}_{2}$ extracts obtained from dry flower stems of Lavandula angustifolia Mill. cultivated in two European countries: Poland and Bulgaria. The $\mathrm{scCO}_{2}$ extracts (L-Pl-E, L-Bg-E) were thoroughly studied according to their physicochemical and antimicrobial properties. In order to evaluate the influence of evaporator temperature (from 55 to $95^{\circ} \mathrm{C}$ ) under vacuum $\left(10^{-2} \mathrm{mbar}\right.$ ) and a constant feed flow rate $(0.833 \mathrm{~mL} / \mathrm{min})$ on the recovery of the target components, gas chromatography equipped with flame ionization detection (GC-FID) analysis was applied. In this study, the in vitro antimicrobial (antibacterial and antifungal) activity of distillates, light oils, and extracts from L. angustifolia Mill. were also investigated.

\section{Results}

\subsection{Composition of Lavender $\mathrm{scCO}_{2}$ Extracts}

Over the last decade, the quality of lavender scent extracted by $\mathrm{scCO}_{2}$ in the pressure ranges of $10-30 \mathrm{MPa}$ and up to $40{ }^{\circ} \mathrm{C}$ were reported on in literature, utilizing either a pilot scale $[11,13]$ or laboratory scale SFE units $[13,14]$. The supercritical extraction of lavender was studied by Nadalin et al. [14]. It was shown that maintaining the pressure at $30 \mathrm{MPa}$ and increasing the temperature to $59^{\circ} \mathrm{C}$ resulted in the highest yield of lavender extract (around $7.5 \mathrm{wt} \%$ ) [14]. In accordance with this reported data, a similar extraction yield was obtained for the extraction of Lavandula angustifolia of Polish origin (L-Pl) in this paper, resulting in $7.05 \mathrm{wt} \%$ as a ratio of the obtained extract mass to the feed mass for the extraction. However, the extraction temperature was significantly lower $\left(40^{\circ} \mathrm{C}\right)$ compared to that applied by Nadalin et al. [14]. The Bulgarian L. angustifolia (L-Bg) was characterized by slightly lower extraction yield $(6.33 \mathrm{wt} \%)$ under analogous extraction conditions. The laboratory-scale investigations mostly aimed to optimize the lavender extraction process, in terms of a high total extraction yield and a relatively high amount of linalool, lavandulol, linalool acetate, and lavandulol acetate $[13,14]$. The increase of lavender flower extraction yield at a constant temperature $\left(40^{\circ} \mathrm{C}\right)$ was noticed when increasing the pressure from 10 to $30 \mathrm{MPa}$ [14]. Under these conditions, higher molecular weight components, such as oxygen-bearing molecules, e.g., coumarins [13], polyphenols [31], and non-volatile cuticular waxes [32], may be co-extracted together with fragrance volatiles [32,33].

The compositions of lavender supercritical fluid extracts have been thoroughly studied in relation to extraction parameters and their impacts on the yields of advantageous flavor components $[13,14,34]$. With the pressure increasing up to $30 \mathrm{Mpa}$ at $40{ }^{\circ} \mathrm{C}$, the $\mathrm{CO}_{2}$ density also increases, which favors higher extraction yields and the apparent solubility of the most characteristic group of lavender odoriferous molecules-oxygenated monoterpenes, i.e., ester or alcohol components [14]. Unavoidably, targeted fragrance molecules are co-extracted with waxy, resinous, and color matter; hence, the product is concrete-like (Figure 1). The $\mathrm{scCO}_{2}$ lavender extract is enriched with scent volatile compounds much more than the oil [35] and, due to preservation of initial plant matter, it can be served as a valuable feedstock for further fractionation and valorization processes [13]. 


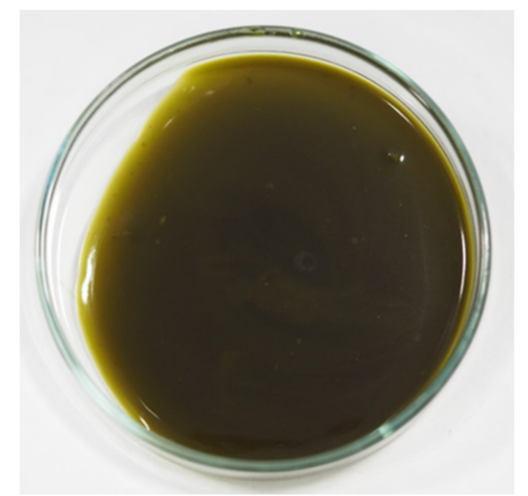

Figure 1. Lavender L-Pl-E scCO $\mathrm{sc}_{2}$ extract.

The extract compositions from the L-Bg-E and L-Pl-E samples were determined by means of the GC-MS qualitative analysis. Results of GC-MS identification and relative amounts of components (\%) are listed in Table 1. Additionally, chromatograms corresponding to each extract are depicted in Figure 2.

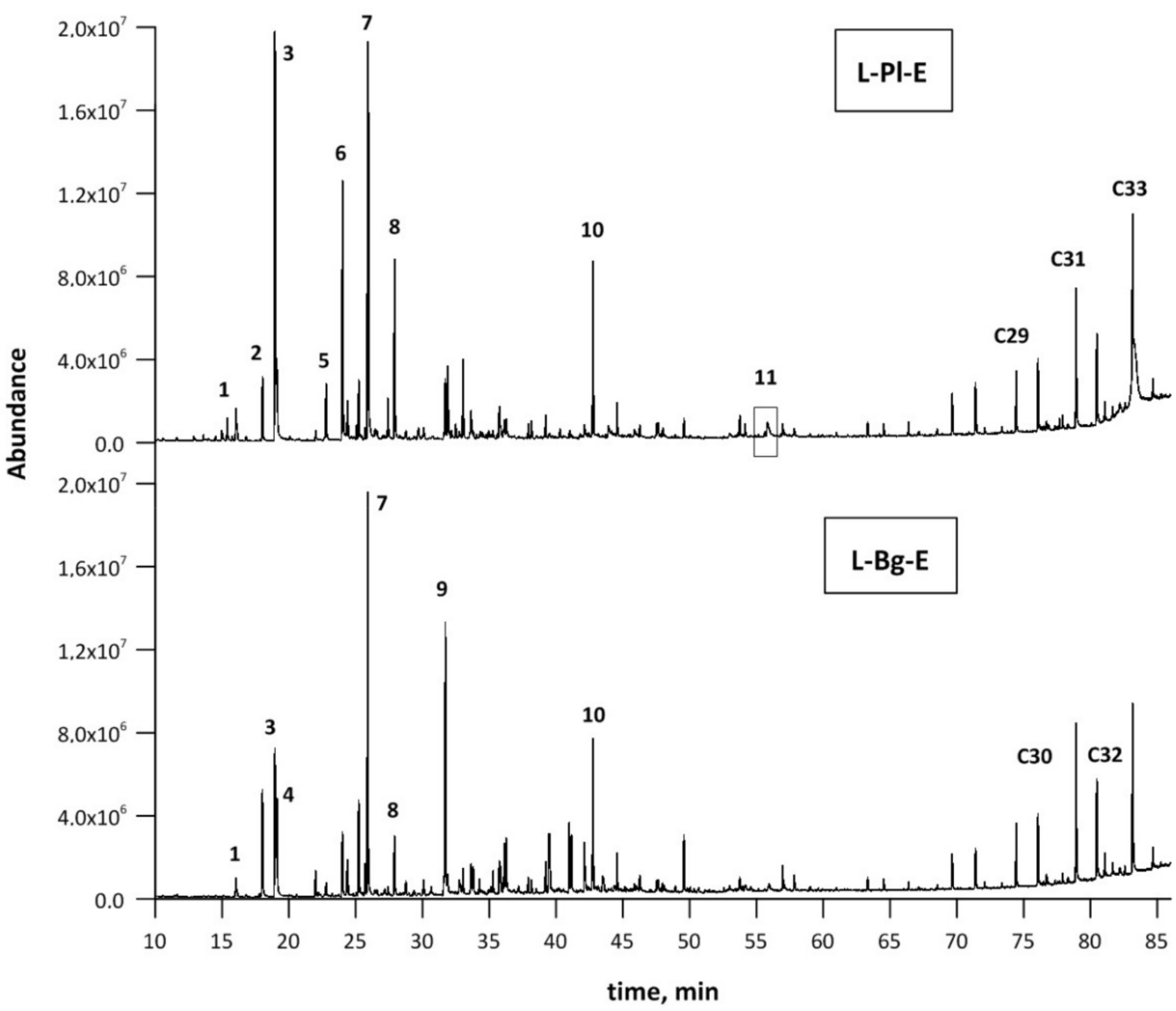

Figure 2. The GC-MS chromatograms of L-Pl-E and L-Bg-E samples. Peaks in order of elution: 3) eucalyptol, 4) cis-furan linalool oxide, 5) linalool, 6) trans-furan linalool oxide, 8) lavandulol, 9) terpinen-4-ol, 14) linalyl acetate, 16) lavandulyl acetate, 21) 3,7-dimethyl-1,7-octadiene-3,6-diol (terpendiol II), 40) caryophyllene oxide, 50) herniarin. 
Table 1. Chemical compositions of lavender $\mathrm{scCO}_{2}$ extracts.

\begin{tabular}{|c|c|c|c|c|c|}
\hline \multirow{2}{*}{ No. } & \multirow{2}{*}{ Compounds } & \multirow{2}{*}{ RI } & \multirow{2}{*}{ RT } & \multicolumn{2}{|c|}{ Composition, $\%$} \\
\hline & & & & L-Pl-E & L-Bg-E \\
\hline 1 & (-)-Limonene & 1114 & 14.99 & 0.26 & - \\
\hline 2 & trans- $\beta$-Ocimene & 1123 & 15.39 & 0.55 & - \\
\hline 3 & Eucalyptol & 1139 & 16.05 & 1.05 & 0.87 \\
\hline 4 & cis-Linalool oxide (furanoid) & 1186 & 18.03 & 1.51 & 3.59 \\
\hline 5 & $\begin{array}{c}\text { Linalool } \\
\text { (3,7-dimethyl-1,6-octadien-3-ol) }\end{array}$ & 1209 & 18.98 & 17.02 & 4.56 \\
\hline 6 & trans-Linalool oxide (furanoid) & 1212 & 19.12 & 1.42 & 3.63 \\
\hline 7 & Lavender lactone & 1278 & 22.01 & 0.26 & 0.79 \\
\hline 8 & Lavandulol & 1295 & 22.79 & 1.40 & 0.43 \\
\hline 9 & Terpinen-4-ol & 1323 & 24.02 & 6.02 & 2.15 \\
\hline 10 & Linalool oxide (pyranoid) & 1332 & 24.40 & 0.95 & 1.55 \\
\hline 11 & $\alpha$-Terpineol & 1348 & 25.08 & 0.28 & - \\
\hline 12 & 2,6-Dimethyl-3,7-octadiene-2,6-diol & 1351 & 25.24 & 1.34 & 2.81 \\
\hline 13 & $\begin{array}{l}\text { 3,7-Dimethyl-1,5- octadiene-3,7-diol } \\
\text { (terpendiol I) }\end{array}$ & 1362 & 25.70 & 0.26 & 0.85 \\
\hline 14 & Linalool acetate & 1367 & 25.93 & 25.68 & 12.78 \\
\hline 15 & Crypton & 1402 & 27.42 & 0.87 & 0.28 \\
\hline 16 & $( \pm)$-Lavandulyl acetate & 1413 & 27.91 & 3.96 & 1.86 \\
\hline 17 & Bornyl acetate & 1433 & 28.76 & - & 0.40 \\
\hline 18 & $p$-Cumic aldehyde & 1456 & 29.71 & 0.35 & - \\
\hline 19 & 2,6-Dimethyl-1,7-octadiene-3,6-diol & 1465 & 30.10 & 0.33 & 0.59 \\
\hline 20 & $\quad p$-Cymen-7-ol & 1501 & 31.59 & - & 0.54 \\
\hline 21 & $\begin{array}{l}\text { 3,7-Dimethyl-1,7-octadiene-3,6-diol, } \\
\text { (terpendiol II) }\end{array}$ & 1504 & 31.71 & 1.41 & 8.16 \\
\hline 22 & Longicyclene & 1508 & 31.90 & 1.61 & 0.7 \\
\hline 23 & $\alpha$-Bergamotene & 1523 & 32.50 & 0.24 & - \\
\hline 24 & $\beta$-Caryophyllene & 1537 & 33.04 & 1.76 & 0.67 \\
\hline 25 & $\beta$-Farnesene & 1551 & 33.64 & 0.89 & 1.13 \\
\hline 26 & $\begin{array}{l}\text { 2,6-Dimethyl-2,7-octadiene-1,6-diol } \\
\text { (8-hydroxylinalool) }\end{array}$ & 1555 & 33.79 & 0.21 & 1.02 \\
\hline 27 & Nerolidol & 1592 & 35.29 & - & 0.69 \\
\hline 28 & $\begin{array}{l}\text { cis-2-Methyl-3-oxo- } \\
\text { cyclohexanebutanal }\end{array}$ & 1604 & 35.76 & 0.86 & 0.92 \\
\hline 29 & cis-9-Tetradecen-1-ol & 1607 & 35.86 & 0.23 & 0.65 \\
\hline 30 & Epoxylinalool & 1614 & 36.14 & 0.49 & 1.55 \\
\hline 31 & Farnesyl formate & 1618 & 36.28 & 0.5 & 1.76 \\
\hline 32 & Nerolidyl acetate & 1661 & 37.93 & 0.32 & 0.48 \\
\hline 33 & $\alpha$-Santalol & 1667 & 38.17 & 0.38 & 0.4 \\
\hline 34 & $\alpha$-Bisabolol & 1694 & 39.22 & 0.44 & 0.84 \\
\hline 35 & $\mathrm{NI}^{\mathrm{a}}$ & 1701 & 39.46 & - & 1.51 \\
\hline 36 & $\mathrm{NI}^{\mathrm{a}}$ & 1703 & 39.54 & - & 1.67 \\
\hline 37 & $\mathrm{NI}^{\mathrm{a}}$ & 1743 & 40.99 & - & 2.06 \\
\hline 38 & $\mathrm{NI}^{\mathrm{a}}$ & 1747 & 41.16 & - & 1.38 \\
\hline 39 & $(1 S, 2 S, 4 S)$-Trihydroxy- $p$-menthane & 1774 & 42.14 & 0.25 & 1.88 \\
\hline 40 & $\beta$-Caryophyllene oxide & 1791 & 42.77 & 3.8 & 4.54 \\
\hline 41 & Coumarin & 1821 & 43.92 & 0.18 & - \\
\hline 42 & tau-Cadinol & 1842 & 44.58 & 0.66 & 1.01 \\
\hline 43 & Ledene oxide-(II) & 1891 & 46.27 & 0.25 & 0.43 \\
\hline 44 & $\alpha$-Santalol & 1929 & 47.55 & 0.27 & 0.3 \\
\hline 45 & $\beta$-Santalol & 1932 & 47.65 & 0.31 & \\
\hline 46 & Hexahydrofarnesyl acetone & 1942 & 47.98 & 0.2 & - \\
\hline 47 & Isolongifolol & 1990 & 49.58 & 0.39 & 1.55 \\
\hline 48 & Neryl acetate & 2121 & 53.76 & 0.51 & 0.43 \\
\hline 49 & Gerany-p-cymene & 2134 & 54.15 & 0.27 & 0.28 \\
\hline 50 & Herniarin & 2189 & 55.83 & 1.13 & 0.38 \\
\hline
\end{tabular}


Table 1. Cont.

\begin{tabular}{lccccc}
\hline \multirow{2}{*}{ No. } & Compounds & RI & RT & \multicolumn{2}{c}{ Composition, $\%$} \\
\cline { 5 - 6 } & & & & L-P1-E & L-Bg-E \\
\hline 51 & Neoisolongifolene, 8-oxo & 2228 & 56.98 & 0.21 & 0.7 \\
52 & 7-Hydroxyfarnesene & 2257 & 57.83 & - & 0.46 \\
53 & 11-Methyltricosane & 2453 & 63.33 & 0.27 & 0.31 \\
54 & Pentacosane, C25 & 2497 & 64.54 & 0.22 & 0.31 \\
55 & 2-Methylhexacosane & 2568 & 66.38 & 0.26 & - \\
56 & Heptacosane, C27 & 2697 & 69.66 & 0.81 & 0.95 \\
57 & 1-Iodo-docosane & 2769 & 71.40 & 1.43 & 1.21 \\
58 & Nonacosane, C29 & 2897 & 74.45 & 1.28 & 1.78 \\
59 & Tetracosane 1-iodo & 2969 & 76.08 & 1.62 & 1.97 \\
60 & Triacontane, C30 & 2996 & 76.72 & - & 0.3 \\
61 & 1-Heptacosanol & 3051 & 77.92 & 0.3 & 0.29 \\
62 & Hentriacontane, C31 & 3097 & 78.93 & 3.14 & 4.68 \\
63 & Methyltriacontane & 3169 & 80.48 & 2.23 & 3.22 \\
64 & Dotriacontane, C32 & 3197 & 81.08 & 0.46 & 0.73 \\
65 & Tritriacontane, C33 & 3297 & 83.16 & 4.57 & 5.43 \\
\hline
\end{tabular}

Compounds identified by mass spectrum and retention index, area (\%) calculated from the total ion current in GC/MS. RI: retention indices, calculated; ${ }^{a}$ No reliable RI data. NI: not identified.

The GC-MS analysis revealed the presence of more than sixty different compounds in the extracts. (Table 1, Figure 2). Linalool and linalool acetate, the main representatives of lavender oxygenated monoterpenes, were the most abundant components; however, their percentages differed notably from one extract to another. The targeted compounds represented the lowest percentage composition in the case of the L-Bg-E sample with $4.56 \%$ and $12.78 \%$ for linalool and linalool acetate, respectively (Table 1). The highest percentages of linalool; linalool acetate and lavandulol; lavandulol acetate and terpinen-4-ol were confirmed in the cases of L-Pl-E (17.02; 25.68; $1.40,3.96$ and 6.02\%, respectively) (Table 1). Lavandulol and its acetate are of a great interest in the cosmetic and perfumery industries, as it gives the oil a rosaceous, sharp floral aroma [36,37]; thus, their higher levels in natural oil can strongly increase its price. Together with linalool, linalyl acetate, terpinen-4-ol, and $\alpha$-terpineol-the compounds were recently selected to study the influence of long-term storage on essential oil content and in the quality of two Czech Lavandula angustifolia Mill. lavender varieties [38]. The gradual lowering of the total content of essential oils $(2.56 \%$ per year) was noticed; however, no statistically significant relationship between their initial compositions and the loss of the selected fragrance key markers in longer-term monitoring were found.

Linalool, one of the most important compounds for the perfume and flavor industries, occurs naturally in Lavandula angustifolia Mill., as two isomers, almost exclusively predominating ${ }^{\circledR}(-)$-linalool (94.1\%) [39]. This enantiomer is a flowery-fresh woody odor, reminiscent of lavender, which, together with an array of its derivatives, is a common constituent of flower and honey extracts obtained from different lavender and citrus sources [40]. Both L-Bg-E and L-Pl-E are characterized by the presence of 8-hydroxylinalool (2,6-dimethyl-2,7-octadiene-1,6-diol) resulting directly from the activity of P450 hydroxylase. Two isomers of 8-hydroxylinalool (E-; Z-) were found to be direct hydroxylation products of linalool, and together with $\alpha$-terpineol, limonene, and nerolidol, were included in citrus honey, indicating their direct delivery from flower nectar [41]. Other products of direct linalool hydroxylation were 8-oxolinalool and 6,7-epoxylinalool [42]. In the lavender extracts studied, cis- and trans-linalool oxides (furanoid) and terpendiol isomers, i.e., 3,7-dimethyl-1,7-octadien-3,6-diol, were analyzed as products originating from further (consecutive) enzymatic reactions of 6,7-epoxylinalool (Table 1, Figure 3). 
<smiles>C=CC(C)(CCC=C(C)C)OC(C)=O</smiles>

linalyl acetate<smiles>C=CC(C)(O)CCC=C(C)C</smiles>

linalool

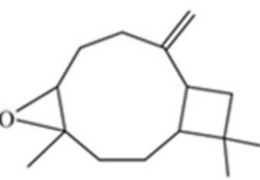

caryophyllene oxide<smiles>C=C(C)C(CC=C(C)C)COC(C)=O</smiles><smiles>[Mg][Mg][Mg][Mg]</smiles><smiles>C=C(C)C(CO)CC=C(C)C</smiles>

lavandulol<smiles>C=C[C@]1(C)CCC(O)C(C)(C)O1</smiles>

pyranoid linalool oxide<smiles>C=CC1(C)CCC(C(C)(C)O)O1</smiles>

furanoid linalool oxide<smiles>C=CC(C)(O)CC=CC(C)(C)O</smiles>

terpendiol I<smiles>C=CC(C)(O)CCC1OC1(C)C</smiles>

6,7-epoxylinalool<smiles>CC1=CCC(O)(C(C)C)CC1</smiles>

terpinen-4-o1<smiles>C=CC(C)(O)CCC=C(C)CO</smiles>

8-hydroxylinalool

Figure 3. Chemical structures of the major and minor compounds identified in lavender $\mathrm{scCO}_{2}$ extracts.

These linalool bioconversion products were previously detected in supercritical lavender extracts obtained under the pressure of $30 \mathrm{MPa}$ and temperatures of $40-50{ }^{\circ} \mathrm{C}$ [13]. Another component previously specified in plant and honey extracts of leatherwood (Eucryphia lucida (Labill.)) and Citrus spp. is 2,6-dimethyl-3,7-octadiene-2,6-diol (precursor of hotrienol) [40], also determined in L-Bg-E and L-Pl-E at the level of 2.81 and 1.34\%, respectively.

Eucalyptol (1,8-cineole) represents the oxygenated monoterpenes providing medicinal and olfactory properties of fine lavender essential oils (Lavandulae aetheroleum) [10]. The richest lavender oils, in terms of the content of such compounds as 1,8-cineole and camphor, are spike lavender oil and lavandin oil Grosso var. [43]. The camphor-based products may be utilized for industrial cleaning products, detergents, or even natural and healthier alternatives to traditional solvents commonly used in fine art painting. However, in Lavandulae aetheroleum, camphor content should not exceed $0.5 \%$ according to EU PDO specifications [43]. High concentrations of camphor, as well as 1,8-cineole and terpinen-4-ol, can adversely affect the quality of lavender natural oils. However, the antimicrobial and antifungal bioactivities for linalool, 1,8-cineole, camphor, terpineol, and isomers of pinene, was proven $[44,45]$.

Other valuable substances of industrial interest, which were found in $\mathrm{scCO}_{2}$ lavender extracts, are sesquiterpenes, hydrocarbons, and their oxygenated forms, including alcohols. The components, i.e., $\beta$-caryophyllene, $\beta$-caryophyllene oxide, $\alpha$-santalene, $\alpha$-santalol, $\beta$ santalol, $\beta$-farnesene, $\alpha$-bergamotene, nerolidol, $\alpha$-bisabolol, tau-cadinol, ledene oxide-(II), were analyzed in both studied extracts (Table 1). However, interpretation in the sesquiterpene region of the chromatogram may be imprecise due to structural similarities of eluted components. $\beta$-Caryophyllene oxide is a predominant sesquiterpenoid representative found in the studied extracts with percentages of 3.80\% (L-Pl-E) and 4.54\% (L-Bg-E). Both 
$\beta$-caryophyllene and its oxidation product $\beta$-caryophyllene oxide are used as cosmetics and food additives since they are approved as fragrance supplements by regulatory authorities, such as the FDA and EFSA [46]. It was reported that SFE conditions enable high concentrations of caryophyllene oxide, linalool, and geranial at $60^{\circ} \mathrm{C}$ and under pressure of $30 \mathrm{MPa}$ [47].

The studied lavender extracts contained other groups of oxygen-bearing components, i.e., lower aliphatic compounds: 1-octen-3-ol, octan-3-one, and characteristic lactones. The last group of lavender compounds includes coumarins and lavender lactone (5-ethenyldihydro-5-methyl-2(3H)-furanone), which is known for its interesting olfactory properties [13]. Along with coumarin, its derivatives (i.e., herniarin) are recognized from their significant pharmacological properties, e.g., antitumor, anti-inflammatory, antibacterial, antifungal, diuretic, analgesic, and cardiovascular [48]. Furthermore, natural coumarin is a desirable ingredient due to its sweet, distinguishing vanilla-like scent with grassy notes, applied either in masculine or feminine perfume compositions, and recognizable as a tonka bean fragrance [44]. Lavandula angustifolia is another source of coumarin and herniarin, extracted from flowers, with the use of supercritical $\mathrm{CO}_{2}$. The quantitative analysis of coumarin and its 7-methoxy derivative in L-Bg-E and L-Pl-E samples, as well as distilled fractions, was performed by supercritical fluid chromatography (SFC). The less soluble and non-volatile paraffins included in the cuticle layer of flower stems are easily co-extracted ("superficial washing"); hence, finally, a higher boiling fraction dilutes the fragrance molecules in this complex matrix [32,33]. According to the GC-MS qualitative analysis, a similarity between the chemical composition of the paraffin fraction found in L-Bg-E and L-Pl-E was found, with predominating hentriacontane (C31) and tritriacontane (C33) in both extracts (Table 1).

\subsection{Thermal Properties of $\mathrm{scCO}_{2}$ Extracts}

Thermal characteristics of lavender extracts were determined by differential scanning calorimetry (DSC). The DSC thermograms recorded during the second heating of L-Bg$\mathrm{E}$ and L-Pl-E samples are depicted in Figure 4 and compared with melting profiles of commercial waxes: carnauba and beewax. Supercritical extracts of L. angustifolia Mill. from two European cultivars, Polish and Bulgarian, have been scarcely studied and compared according to the compositions of their waxy fractions.
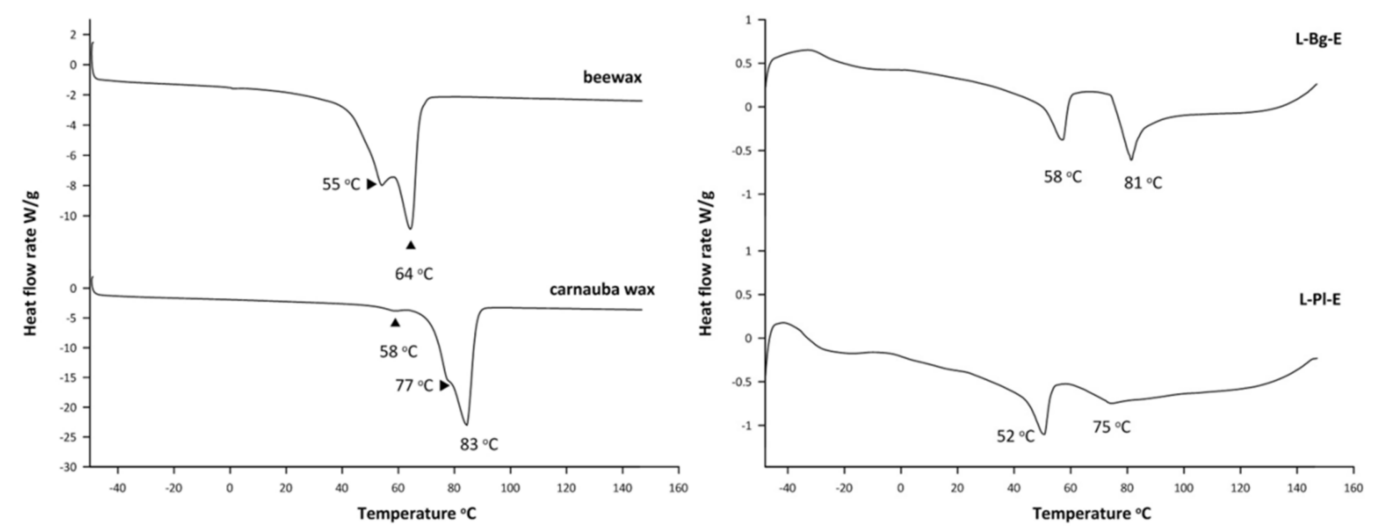

Figure 4. The second heating DSC graphs of lavender $\mathrm{scCO}_{2}$ extracts and commercial waxes: beewax and carnauba wax.

The DSC profiles of L-Bg-E and L-Pl-E showed two endotherms in each analyzed sample (Figure 4). The melting points of L-Bg-E were at $58{ }^{\circ} \mathrm{C}$ and $81{ }^{\circ} \mathrm{C}$, while that of L-Pl-E appeared to be at $52{ }^{\circ} \mathrm{C}$ as the most intensive peak and $75{ }^{\circ} \mathrm{C}$ at a much lower intensity. Both thermograms may suggest coexistence of two different waxy structures in the lipid mixtures of lavender $\mathrm{scCO}_{2}$ extracts and, thus, their multicomponent natures. Lower melting fractions signified by the first peaks $\left(58{ }^{\circ} \mathrm{C}\right.$ and $\left.52{ }^{\circ} \mathrm{C}\right)$ in the heat flow 
curves of L-Bg-E and L-Pl-E, respectively, were also found at DSC curves of beewax $\left(55^{\circ} \mathrm{C}\right)$ and carnauba wax $\left(58^{\circ} \mathrm{C}\right)$, (Figure 4). In the case of a beewax heat flow curve, the peaks at $40-60{ }^{\circ} \mathrm{C}$ were attributed to the heat absorption of free fatty acids (13\%) and hydrocarbons $(13 \%)$ [49]. Both groups of components were qualified in lavender $\mathrm{scCO}_{2}$ extracts with predominating oleic and linoleic fatty acids (analyzed as methyl esters), and long-chain alkanes (C31-C33), Table 1.

The DSC scans of both lavender extracts did not give endotherms at $60{ }^{\circ} \mathrm{C}$ to $70{ }^{\circ} \mathrm{C}$, which could approve fatty acids esters. This fraction was abundant in beewax $(72 \%)$ and led to the sharp absorbing peak at $60-70{ }^{\circ} \mathrm{C}$ [49].

Carnauba wax is noticeably different than beeswax and its chemical composition and physical properties are discussed elsewhere [50-52]. Carnauba wax contains major proportions of esters of hydroxy acids, i.e., $p$-methoxycinnamic diesters (PCO-C), which isolates as a pure fraction, showing up in the DSC curve as an endothermic peak at $73{ }^{\circ} \mathrm{C}$ with a shoulder at $66{ }^{\circ} \mathrm{C}$ [53]. Similar structures could be responsible for some minor features in the second heat thermal analysis of L-Pl-E found at $75^{\circ} \mathrm{C}$ (Figure 3). However, further increase of melting properties was supposed to be affected by the addition of methoxy substituent on the phenol ring, and such behavior was observed for $p$-coumaric acid esters, i.e., methyl ferulate and methyl sinapate, showing fusion points of 62 and $88^{\circ} \mathrm{C}$, respectively [54]. This might support the similarity between the highest melting fractions of L-Bg-E $\left(81^{\circ} \mathrm{C}\right)$ and carnauba wax $\left(83^{\circ} \mathrm{C}\right)$ in terms of carboxylic acid constituents (Figure 4).

The difference between L-Bg-E and L-Pl-E reflected in DSC thermograms at the most intensive melting points may indicate that the waxy structures of both L. angustifolia raw materials depend on its geographic source. Since Bulgarian lavender cultivars are grown on the sunny slopes in a warm and dry climate, the compositions of their cutin layers, covering flowering stems and petals of flowers, give the film excellent barrier properties against UV radiation and uncontrolled water loss. The presence of a higher melting fraction depicted as a sharp peak at $81^{\circ} \mathrm{C}$ (Figure 4) may suggest an increased proportion of phenol constituents lipophilized through its esterification. The isolation of those bioavailable natural components with antiradical properties can widen diverse uses of lavender, acknowledged in the cosmetic and pharmaceutical industries.

\subsection{Application of Molecular Distillation in Lavender $\mathrm{scCO}_{2}$ Extract Fractionation}

Molecular distillation is a type of vacuum distillation that separates components of a mixture by their difference in volatility. A distillation unit designed for short-path operations (molecular distillation) is made up of evaporator and internal spiral condensers placed in its center. The distance from the evaporation surface to the condensation surface does not exceed the mean free path of molecules, which means that, once evaporated, they reach the condensing surface without delay. Additionally, due to specific working conditions provided in the system by a vacuum pump set (0.1-100 $\mathrm{Pa})$, the relative volatility of compounds increases, which allows separation of mixture components at lower temperature. For the optimal product distribution, the feed product is pumped on top of a rotating wiper basket plate, before it is mixed to a thin film by a wiper system. The most important for the system is that it ensures a short residence time of complex mixtures in the distillation unit and largely prevents thermal decomposition of their components, divided during the process into distillate and/or residue streams.

The objective of the present study was to evaluate the potential of a selected approach, to incorporate fractionation under vacuum into the refinement of $\mathrm{scCO}_{2}$ produced lavender extracts. Molecular distillation as a gentle technique of physical refining was applied to separate essential oil components from heavy components co-extracted with $\mathrm{scCO}_{2}$ on a pilot scale. Hence, it was feasible to recover higher yields of precious oxygenated monoterpenes from $\mathrm{scCO}_{2}$ extracts enriched under the selected conditions $\left(30 \mathrm{MPa}, 40{ }^{\circ} \mathrm{C}\right)$. The SFE-MD strategy was already found to be more efficient in a separation of essential oils from artemisia argyi Lévl. Et Vant, compared to hydrodistillation described as time- and energy-consuming and destructive for thermolabile compounds (high water abundance and 
high process temperatures leading to hydrolysis) [28]. What is more important, the latter mentioned disadvantage is crucial to overcome especially in relation to recovery of linalyl and lavandulyl acetates. Caryophyllene oxide is one of the highest boiling constituents identified in the lavender essential oil analyzed with GC-MS [55]. However, the boiling point of lavender essential oil $\left(204^{\circ} \mathrm{C}\right)$ as a mixture is a function of the vapor pressures of its major and minor volatile constituents. Coumarin and herniarin are representatives of lactones, which, similar to monoterpenoids, are abundant components of $\mathrm{scCO}_{2}$ extracts obtained under increased extractant density [13]. Thus, the highest boiling components from the studied group of volatiles can also feed the distillate stream, depending on the applied molecular distillation conditions.

The essential oils included in the $\mathrm{scCO}_{2}$ lavender extracts (Figure 1) are diluted with higher boiling components with a waxy character, causing congelation at room temperature. The studied feedstocks differed slightly in densities between L-Bg-E and L-Pl-E $(0.98 \mathrm{~g} / \mathrm{mL}$ and $0.93 \mathrm{~g} / \mathrm{mL}$, respectively) and in composition/proportion to a higher melting fraction, as confirmed by the DSC curve of L-Bg-E $\left(81^{\circ} \mathrm{C}\right)$. Those features of lavender extracts may further impact the performance of thin film evaporator. The boiling points of the studied volatiles are listed in Table 2.

Table 2. Boiling and melting points of oxygenated monoterpenes, caryophyllene oxide, and coumarins.

\begin{tabular}{ccccc}
\hline Compounds & Formula & $\begin{array}{c}\text { Molecular } \\
\text { Weight, g/mol }\end{array}$ & $\begin{array}{c}\text { Boiling Point, } \\
{ }^{\circ} \mathbf{C}\end{array}$ & $\begin{array}{c}\text { Melting Point, } \\
{ }^{\circ} \mathbf{C}\end{array}$ \\
\hline Coumarin & $\mathrm{C}_{9} \mathrm{H}_{6} \mathrm{O}_{2}$ & 146.14 & 301.7 & $68-70$ \\
1,8-Cineole & $\mathrm{C}_{10} \mathrm{H}_{18} \mathrm{O}$ & 154.24 & 176.5 & 2.9 \\
Linalool & $\mathrm{C}_{10} \mathrm{H}_{18} \mathrm{O}$ & 154.25 & 198 & $<-20$ \\
Terpinen-4-ol & $\mathrm{C}_{10} \mathrm{H}_{18} \mathrm{O}$ & 154.25 & $211-213$ & - \\
Lavandulol & $\mathrm{C}_{10} \mathrm{H}_{18} \mathrm{O}$ & 154.26 & $229-230$ & - \\
Herniarin & $\mathrm{C}_{10} \mathrm{H}_{8} \mathrm{O}_{3}$ & 176.16 & 335.3 & $117-121$ \\
Linalyl acetate & $\mathrm{C}_{12} \mathrm{H}_{20} \mathrm{O}_{2}$ & 196.29 & 220 & $<25$ \\
Lavandulyl acetate & $\mathrm{C}_{12} \mathrm{H}_{20} \mathrm{O}_{2}$ & 196.29 & $228-229$ & -17.12 \\
Caryophyllene oxide & $\mathrm{C}_{15} \mathrm{H}_{24} \mathrm{O}$ & 220.35 & 279.7 & $60-62$ \\
\hline
\end{tabular}

For the purpose of the experiment, fractionation was performed under the pressure down to $1 \mathrm{~Pa}$ and the temperature below $100{ }^{\circ} \mathrm{C}$, to assure mild processing conditions for major constituents of lavender aroma. The rest of the crucial parameters were checked and adjusted individually to each extract. The experimental conditions of molecular distillation processes performed on L-Bg-E and L-Pl-E feedstocks are listed in Table 3.

Accordingly, as can be seen in Table 3, the temperatures of the feed tank (FT) were different in order to keep L-Bg-E and L-Pl-E in a liquid form at $50{ }^{\circ} \mathrm{C}$ and $45^{\circ} \mathrm{C}$, respectively. The values of the evaporator temperatures (EVT) and condenser temperature (CTs) were chosen individually to each of the studied lavender $\mathrm{scCO}_{2}$ extracts, based on the first distillate drops falling down the condenser. Since there was no oil distilled out at $50{ }^{\circ} \mathrm{C}$ and below that temperature, $55^{\circ} \mathrm{C}$ was chosen as the initial EVT for both extracts, and five experiments with evaporator temperatures ranging from $55{ }^{\circ} \mathrm{C}$ to $95{ }^{\circ} \mathrm{C}$, with an interval of $10^{\circ} \mathrm{C}$, were performed with a constant feed flow (FF) rate of $0.833 \mathrm{~mL} / \mathrm{min}$ on L-Bg-E and L-Pl-E (Table 3). The CT temperature was kept constant at $10^{\circ} \mathrm{C}$ during the entire distillation experiment of the L-Pl-E extract, while it was varied from $-5^{\circ} \mathrm{C}$ to $6{ }^{\circ} \mathrm{C}$ in distillations D1-D5 in the case of L-Bg-E fractionation. Additionally, the residue discharge temperature ( $\mathrm{RdT}$ ) was raised in a stepwise fashion from $55^{\circ} \mathrm{C}$ to $70^{\circ} \mathrm{C}$ in $\mathrm{D} 1-\mathrm{D} 5$ distillations of L-Bg-E to keep fluidity of the residue stream. 
Table 3. Conditions for molecular distillation of L-Bg-E and L-Pl-E.

\begin{tabular}{|c|c|c|c|c|c|c|c|}
\hline \multicolumn{8}{|c|}{ Parameters } \\
\hline Exp. & FT, ${ }^{\circ} \mathrm{C}$ & $\mathrm{RdT},{ }^{\circ} \mathrm{C}$ & EVT, ${ }^{\circ} \mathrm{C}$ & $\mathrm{CT},{ }^{\circ} \mathrm{C}$ & $\mathrm{FF}, \mathrm{mL} / \mathrm{min}$ & $\mathrm{p}, \mathrm{Pa}$ & rpm \\
\hline \multicolumn{8}{|c|}{ Bulgarian lavender } \\
\hline L-Bg D1 & \multirow{5}{*}{50} & 55 & 55 & -5 & \multirow{5}{*}{0.833} & \multirow{5}{*}{$\sim 1 \mathrm{~Pa}\left(10^{-2} \mathrm{mbar}\right)$} & \multirow{5}{*}{350} \\
\hline L-Bg D2 & & 58 & 65 & -5 & & & \\
\hline L-Bg D3 & & 63 & 75 & 0 & & & \\
\hline L-Bg D4 & & 68 & 85 & 6 & & & \\
\hline L-Bg D5 & & 70 & 95 & 6 & & & \\
\hline \multicolumn{8}{|c|}{ Polish lavender } \\
\hline L-P1 D1 & \multirow{5}{*}{45} & \multirow{5}{*}{55} & 55 & \multirow{5}{*}{10} & \multirow{5}{*}{0.833} & \multirow{5}{*}{$\sim 1 \mathrm{~Pa}\left(10^{-2} \mathrm{mbar}\right)$} & \multirow{5}{*}{200} \\
\hline L-P1 D2 & & & 65 & & & & \\
\hline L-P1 D3 & & & 75 & & & & \\
\hline L-Pl D4 & & & 85 & & & & \\
\hline L-P1 D5 & & & 95 & & & & \\
\hline
\end{tabular}

FT—feed tank temperature; RdT—residue discharge temperature; EVT—evaporator temperature; CT—condenser temperature; FF—-feed flow rate; $\mathrm{p}$-pressure; D—distillate; rpm—wiper basket speed.

\subsection{The Effect of EVT on Distillate Enrichment with Key Lavender Fragrance Molecules}

The lavender extracts were submitted to MD experiments, which were performed with evaporator temperatures (EVT) ranging from $55{ }^{\circ} \mathrm{C}$ to $95{ }^{\circ} \mathrm{C}$ (five experiments per extract), at a constant pressure $(1 \mathrm{~Pa})$ and under a constant feed flow rate (FF) of $0.833 \mathrm{~mL} / \mathrm{min}$ (Table 4). The results were analyzed in terms of contents of targeted oxygenates $(\mathrm{mg} / \mathrm{g})$ in the obtained distillates and the ratio of distillate stream mass to residue stream mass $(D / R)$ obtained at every single step of the MD processes (D1-D5).

Table 4. Parameters to evaluate the molecular distillation of lavender $\mathrm{scCO}_{2}$ extracts.

\begin{tabular}{|c|c|c|c|c|c|c|c|c|c|}
\hline \multirow{2}{*}{ EVT, ${ }^{\circ} \mathrm{C}$} & \multirow{2}{*}{$\mathrm{CT},{ }^{\circ} \mathrm{C}$} & \multirow{2}{*}{ Fraction } & \multirow{2}{*}{$\% w t_{D}$} & \multirow{2}{*}{$\% w_{R}$} & \multirow{2}{*}{$\mathrm{D} / \mathrm{R}$} & \multicolumn{2}{|c|}{$\%$ wt $_{\mathrm{CT}}$} & \multirow{2}{*}{$\%$ wt } & \multirow{2}{*}{ Rec. } \\
\hline & & & & & & Oil & Water & & \\
\hline \multicolumn{10}{|c|}{ Bulgarian lavender } \\
\hline 55 & -5 & L-Bg-D1 & 15.23 & 75.73 & 0.20 & 1.73 & 3.46 & 3.85 & 20.2 \\
\hline 65 & -5 & L-Bg-D2 & 20.12 & 70.54 & 0.29 & 1.88 & 3.38 & 4.08 & 30.3 \\
\hline 75 & 0 & L-Bg-D3 & 34.87 & 55.51 & 0.63 & 2.32 & 3.54 & 3.76 & 64.0 \\
\hline 85 & 6 & L-Bg-D4 & 39.28 & 51.12 & 0.77 & 2.20 & 3.50 & 3.90 & 81.4 \\
\hline 95 & 6 & L-Bg-D5 & 44.65 & 44.86 & 1.00 & 3.12 & 3.25 & 4.12 & 82.8 \\
\hline \multicolumn{10}{|c|}{ Polish lavender } \\
\hline 55 & \multirow{5}{*}{10} & L-Pl-D1 & 19.13 & 70.31 & 0.27 & 3.32 & 3.12 & 4.12 & 23.9 \\
\hline 65 & & L-Pl-D2 & 24.86 & 64.43 & 0.39 & 3.15 & 3.31 & 4.25 & 37.2 \\
\hline 75 & & L-Pl-D3 & 35.33 & 53.81 & 0.66 & 3.23 & 3.25 & 4.38 & 61.2 \\
\hline 85 & & L-Pl-D4 & 44.44 & 44.06 & 1.01 & 3.70 & 3.30 & 4.50 & 86.6 \\
\hline 95 & & L-Pl-D5 & 45.28 & 42.05 & 1.08 & 4.53 & 3.42 & 4.72 & 88.1 \\
\hline
\end{tabular}

EVT-evaporator temperature; CT—condenser temperature; \%wt-material loss, \%wt of distillate stream; $\% \mathrm{wt}_{\mathrm{R}}$-the percentage weight of residue stream; $\mathrm{D} / \mathrm{R}$-ratio of distillate to residue; $\% \mathrm{wt} \mathrm{CT}_{\mathrm{T}}$ the percentage weight of cold trap fraction; Rec.-recovery.

According to Tovar et al. [20], two parameters were important for effective separation of citral from lemongrass essential oil, i.e., EVT and FF. The last parameter, FF, was kept 
the same during both MD processes, while EVT was increased stepwise from 55 to $95{ }^{\circ} \mathrm{C}$ (Table 3). However, processing of L-Bg-E appeared to be more difficult in terms of a mass and heat transfer and required adjusting more parameters at the same time, compared to MD of L-Pl-E (Table 3). Different physicochemical properties of L-Bg-E, and its "congelation" over the distillation time, required maintaining a higher wiper basket speed of $350 \mathrm{rpm}$. Constant mixing of the falling film caused by the roller wiper action provided the heat transfer into deeper layers of the extracts more abundant with volatile molecules, and favored their concentrations in the vapor phase. The faster wiper basket movement (more rotations per minute) and increased evaporation efficiency resulted in intensified condensation. Hence, in order to ensure concentrations of the desired lavender fragrance components in the distillate stream, and to minimize material loss in the vapor phase and condense in the cold trap, the CT temperature was adjusted (changed from $-5{ }^{\circ} \mathrm{C}$ to $6{ }^{\circ} \mathrm{C}$ in distillations D1-D5) at each stage of the L-Bg-E processing (Table 3). Low amounts of material condensed in the trap (lower than $8 \%$ ) of the vacuum system previously found an indicator of the effective separation [20]. The yields of water and light oil (\%wt $\mathrm{CT}_{\mathrm{T}}$, collected after each stage of MD of both lavender extracts did not exceed, in total, $8 \%$ (Table 4). However, the loss of light oil increased with the increase of the EVT, to the maximum level at $95^{\circ} \mathrm{C}$.

Additionally, with the highest applied EVT favoring highest recovery of the lower boiling fraction, the viscosity of a residual part increased and, consequently, the residue discharge temperature was increased up to $70^{\circ} \mathrm{C}$ (Table 3). Further processing of L-Bg-E under selected conditions with higher EVT exceeding $95^{\circ} \mathrm{C}$ can be unworkable because of the residue viscosity.

Results show that, with increasing EVTs, the percentage weight of the distillate stream $\left(\% w t_{D}\right)$ also increased (Table 4$)$. The highest values of $\% w t_{D}$ and, thus, the highest split ratio (D/R), were obtained for experiments D4 and D5, with EVTs of $85{ }^{\circ} \mathrm{C}$ and $95{ }^{\circ} \mathrm{C}$, respectively. The highest was also the percentage weight of the cold trap fraction $\left(\% \mathrm{ot}_{\mathrm{CT}}\right)$, referring to the content of water and light oil collected in the direct cooled cold trap $\left(-80{ }^{\circ} \mathrm{C}\right)$. However, removal of the light oil fraction from L-Pl-E proceeding with increasing EVTs $\left(55-95^{\circ} \mathrm{C}\right)$ did not affect the viscosity of residuals as much as in the case of L-Bg-E. Hence, the RdT was quite low and remained unchanged over processing of L-Pl-E up to an EVT of $95^{\circ} \mathrm{C}$. A further slight increase in EVT might cause a further increase in $\% w t_{D}$ and enhance recovery of oxygenated compounds in the stream of distillates. In the example of citral, Tovar et al. [20] confirmed that with the highest applied EVT $\left(60-120{ }^{\circ} \mathrm{C}\right)$ and the highest feed flow rate $(1.5-4.5 \mathrm{~mL} / \mathrm{min})$, the concentration of this compound in the distillate stream doubled to $40.963 \mathrm{mg} / \mathrm{mL}$ compared to the initial concentration, proving the high product quality. However, according to Li et al. [27], the EVT exceeding $120{ }^{\circ} \mathrm{C}$ was found deleterious for $\mathrm{scCO}_{2}$ extract of Artemisia annua separated with MD under a similar vacuum $(1.67 \mathrm{~Pa})$. The combination of SFE and MD purification methods below $120{ }^{\circ} \mathrm{C}$ allowed producing high-quality essential oils, mainly composed of limonene, $(1 S, 5 S)-\alpha-$ pinene, $\beta$-pinene, $\beta$-farnesene, $\alpha$-caryophyllene, and $\gamma$-elemene, exhibiting antimicrobial and antioxidant activities [27].

The contents of target oxygenates quantified in lavender distillates obtained in the applied EVT range $\left(55-95^{\circ} \mathrm{C}\right)$ are listed in Table 5. The increase of EVT was crucial for the increase in contents of oxygenated monoterpenes and caryophyllene oxide in the distillate streams of both processed lavender extracts. Once the EVT increased up to $85^{\circ} \mathrm{C}$, the contents of 1,8-cineole, linalool, linalyl acetate, terpinen-4-ol, lavandulyl acetate, lavandulol, and caryophyllene oxide increased 2.0-2.4 times (L-Pl-D4) and 2.0-2.2 times (L-Bg-D4) in relation to the crude extracts (Table 5). 
Table 5. The fractionation results of L-Bg-E and L-PL-E during molecular distillation.

\begin{tabular}{|c|c|c|c|c|c|c|c|c|c|c|}
\hline \multirow{3}{*}{ Stream } & \multirow{3}{*}{$\mathrm{EVT},{ }^{\circ} \mathrm{C}$} & \multicolumn{9}{|c|}{ Compounds } \\
\hline & & $1 *$ & $2 *$ & $3 * *$ & $4 * *$ & $5 * *$ & $6^{* *}$ & $7^{* *}$ & $8^{* *}$ & $9 * *$ \\
\hline & & \multicolumn{9}{|c|}{ Content, mg/g } \\
\hline L-Bg-E & - & 7.00 & 5.30 & 1.85 & 19.60 & 51.54 & 2.32 & 20.38 & 7.46 & 6.02 \\
\hline D1 & 55 & 8.48 & 3.79 & 3.03 & 25.10 & 75.80 & 3.22 & 25.85 & 9.53 & 8.22 \\
\hline D2 & 65 & 6.52 & 4.11 & 3.55 & 31.34 & 82.24 & 3.54 & 32.12 & 11.51 & 9.64 \\
\hline D3 & 75 & 5.46 & 4.25 & 4.02 & 37.52 & 107.45 & 4.23 & 36.76 & 14.38 & 11.61 \\
\hline D4 & 85 & 5.66 & 4.43 & 4.20 & 39.24 & 118.41 & 4.80 & 45.55 & 18.14 & 13.80 \\
\hline \multicolumn{2}{|c|}{ T-C-D4 } & 0.80 & 0.80 & 2.30 & 2.00 & 2.30 & 2.10 & 2.20 & 2.40 & 2.30 \\
\hline D5 & 95 & 5.59 & 4.85 & 3.74 & 34.94 & 105.40 & 4.27 & 40.55 & 16.14 & 12.20 \\
\hline L-Pl-E & - & 14.89 & 11.07 & 1.65 & 59.16 & 89.53 & 8.96 & 43.61 & 14.40 & 15.88 \\
\hline D1 & 55 & 14.11 & 7.58 & 2.48 & 75.34 & 127.54 & 10.32 & 50.45 & 15.81 & 19.65 \\
\hline D2 & 65 & 12.84 & 6.53 & 2.73 & 95.39 & 146.76 & 12.87 & 65.39 & 19.25 & 26.84 \\
\hline D3 & 75 & 10.49 & 5.12 & 3.07 & 112.80 & 165.87 & 15.89 & 88.22 & 24.32 & 29.32 \\
\hline D4 & 85 & 8.95 & 4.30 & 3.22 & 131.79 & 185.73 & 18.95 & 92.53 & 29.67 & 34.75 \\
\hline \multicolumn{2}{|c|}{ T-C-D4 } & 0.60 & 0.40 & 2.00 & 2.20 & 2.10 & 2.10 & 2.10 & 2.20 & 2.10 \\
\hline D5 & 95 & 9.12 & 4.24 & 3.28 & 130.23 & 184.42 & 19.03 & 93.15 & 30.20 & 34.87 \\
\hline & & $\begin{array}{l}{ }^{*} \mathrm{Co} \\
\mathrm{GC}- \\
\text { lava } \\
\text { disti }\end{array}$ & $\begin{array}{l}\text { s on } \\
\text { alysis } \\
9-\mathrm{c} \\
4 \text { ) rel }\end{array}$ & $\begin{array}{l}\text { of } U \\
\text { cine } \\
\text { lene } \\
\text { heir c }\end{array}$ & $\begin{array}{l}\text { lalysis (1 } \\
\text {-linalool, } \\
\text { T-C-D4, } \\
\text { cations in }\end{array}$ & $\begin{array}{l}\text { umari } \\
\text { linalyl } \\
\text { nber of } \\
\text { corres }\end{array}$ & $\begin{array}{l}\text { eerniar } \\
\text {; 6-te } \\
\text { that co } \\
\text { g extra }\end{array}$ & $\begin{array}{l}\text { oxyg } \\
\text { ene-4-c } \\
\text { nents } 1 \\
\text { mples }\end{array}$ & $\begin{array}{l}\text { compo } \\
\text { avandu } \\
\text { ere conc } \\
\text { E or L-P }\end{array}$ & $\begin{array}{l}\text { based } \\
\text { cetate; } \\
\text { ated in }\end{array}$ \\
\hline
\end{tabular}

Linalool, lavandulyl acetate, and linalyl acetate, the most abundant oxygenated ingredients of L-Bg-E and L-Pl-E, differed in contents between both feedstocks. They were quantified at almost twice lower levels in L-Bg-E than in L-Pl-E (Table 5). The same applied to terpinen-4-ol, lavandulol, and caryophyllene oxide. In the case of L-Pl-E, the content of these three oxygenated compounds quantified by GC-FID were 59.16, 43.61, and $89.53 \mathrm{mg} / \mathrm{g}$, respectively. The contents of linalool, lavandulyl acetate, and linalyl acetate gradually increased in the distillates across stages with a maximum in L-Pl-D4 (131.79, 92.53 and $185.73 \mathrm{mg} / \mathrm{g}$, respectively) (Table 5). However, the increase of EVT from $85^{\circ} \mathrm{C}$ to $95{ }^{\circ} \mathrm{C}$ caused a slight decrease in contents of those monoterpenoids (except from coumarins and caryophyllene oxide) compared to distillates L-Pl D4. The contents of less abundant monoterpenoids in L-Pl-E: 1,8 -cineole $(1.65 \mathrm{mg} / \mathrm{g})$, terpinen-4-ol $(8.96 \mathrm{mg} / \mathrm{g})$, lavandulol $(14.40 \mathrm{mg} / \mathrm{g})$, and caryophyllene oxide $(15.88 \mathrm{mg} / \mathrm{g})$ also increased twice after MD at an EVT of $85^{\circ} \mathrm{C}$. A further increase in EVT by $10^{\circ} \mathrm{C}$ caused a slight increase in those contents.

The content of 1,8-cineole was similar in both lavender extracts and was concentrated to the same extent (2.3-times for L-Bg-E and two-times in L-Pl-E) upon increasing the EVT to $85^{\circ} \mathrm{C}$. According to Table 5, the molecular distillation of L-Bg-E under the highest applied EVT of $95^{\circ} \mathrm{C}$ generally caused a greater decrease in contents of monoterpenoids and caryophyllene oxide in the distillate compared to L-Pl-E. This might be an effect of dilution since the second heating DSC graph of the L-Bg-D5 distillate revealed a solidliquid melting transition at $115^{\circ} \mathrm{C}$ (Figure 5). The co-distilled higher-boiling components caused a slight cloudiness of L-Bg-D5 chilled to $-4^{\circ} \mathrm{C}$. 


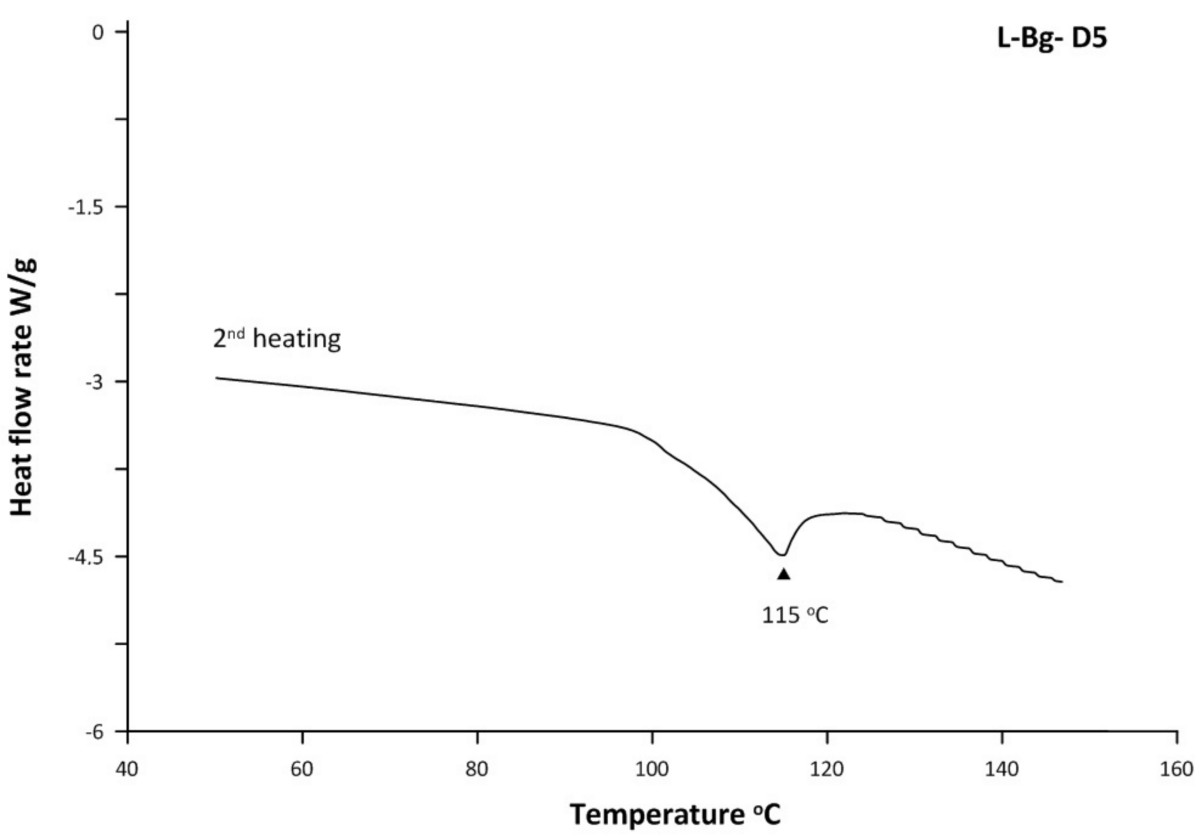

Figure 5. The second heating DSC graph of the L-Bg D5 distillate.

The molecular distillation of L-Pl-E under the highest applied EVT temperature of $95{ }^{\circ} \mathrm{C}$ neither caused a significant change in D/R nor in the contents of the oxygenated monoterpenes compared to the process performed at $85^{\circ} \mathrm{C}$ (Table 5). At the same time, it was noticed that the amount of the cold trap fractions $\left(\% \mathrm{wt}_{\mathrm{CT}}\right)$ collected in a glass cylinder covering a steely cool finger $\left(-80^{\circ} \mathrm{C}\right)$ increased remarkably after the distillation process at $95{ }^{\circ} \mathrm{C}$ (experiment D5) of L-Pl-E, yielding, in total, 7.95\%. The essential oil condensed with water and then separated as a lighter layer was the predominating cold trap material $(4.53 \%)$. Thus, the use of EVT $=95{ }^{\circ} \mathrm{C}$ only slightly influenced the fraction L-Pl-D5, compared with L-Pl-D4. At the same time, lighter fragrance components were intensified in the vapor phase as the loss and were collected in the cold trap.

Coumarin and herniarin were the less volatile components amongst the analyzed oxygenated molecules (Table 3) co-distilled in some parts with oxygenated monoterpenes. According to the SFC analysis, it was confirmed that the yield of coumarin was higher than herniarin in both studied extracts (L-Pl-E and L-Bg-E). However, similar to the content of monoterpenoids, the content of both coumarins was almost twice higher in L-Pl-E compared to L-Bg-E (25.96 vs. $12.30 \mathrm{mg} / \mathrm{g}$ ). Although both components were detected in distillates D1-D5 obtained from both feedstocks, their contents under processing conditions were lower than in the initial extract samples.

The other co-distilled components affecting the quality of oxygenated monoterpenes were pigments, which influenced the yellowish color of the distillates. Figure 6 depicts distillates (L-Pl-D4 and L-Bg-D4) obtained at EVT of $85^{\circ} \mathrm{C}$, light oil fractions collected after the process (L-Pl-O and L-Bg-O), and yellow-green residue fractions (L-Pl-R4 and $\mathrm{L}-\mathrm{Bg}-\mathrm{R} 4, \mathrm{EVT}=85^{\circ} \mathrm{C}$ ) obtained in the process based on parameters listed in Table 4 . The distillates and colorless light oil fractions were used in the following tests of quality and antimicrobial activities. 

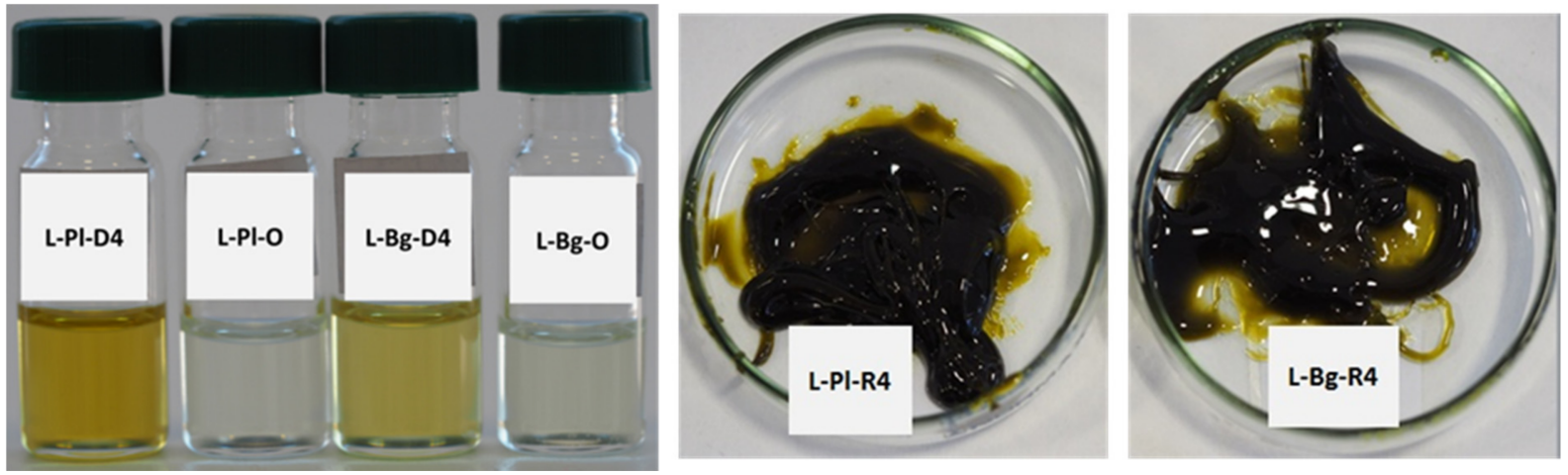

Figure 6. Fractions obtained from molecular distillation of L-Pl-E and L-Bg-E at EVT $=85^{\circ} \mathrm{C}$; O - light oil products; $\mathrm{R}$-residues after molecular distillation.

\subsection{Quality Evaluation of Distillates and Light Oil Fractions}

A non-targeted fingerprint HATR-FTIR analysis was performed to evaluate aromatic lavender concentrated fractions. Recently, vibrational spectroscopy methods, including mid- (MIR) and near-infrared (NIR), combined with chemometric data analyses, were used to confirm the identity and quality of lavender essential oils for commercial purposes [56,57]. Mid-infrared spectroscopy, primarily used qualitatively, provides structural characterization according to the functional group vibration and fingerprint region, which are crucial for molecular identification. The GC-MS is another technique, an alternative one, used for the quality assessment of concentrated fractions, i.e., distillates and light oils (cold trap fractions). The HATR-FTIR mid-infrared spectra of lavender distillates (L-Pl-D4 and L-Bg-D4) and light oil fractions (L-Pl-O and L-Bg-O) obtained from studied lavender extracts; L-Pl-E and L-Bg-E are depicted in Figures 7 and 8, respectively.

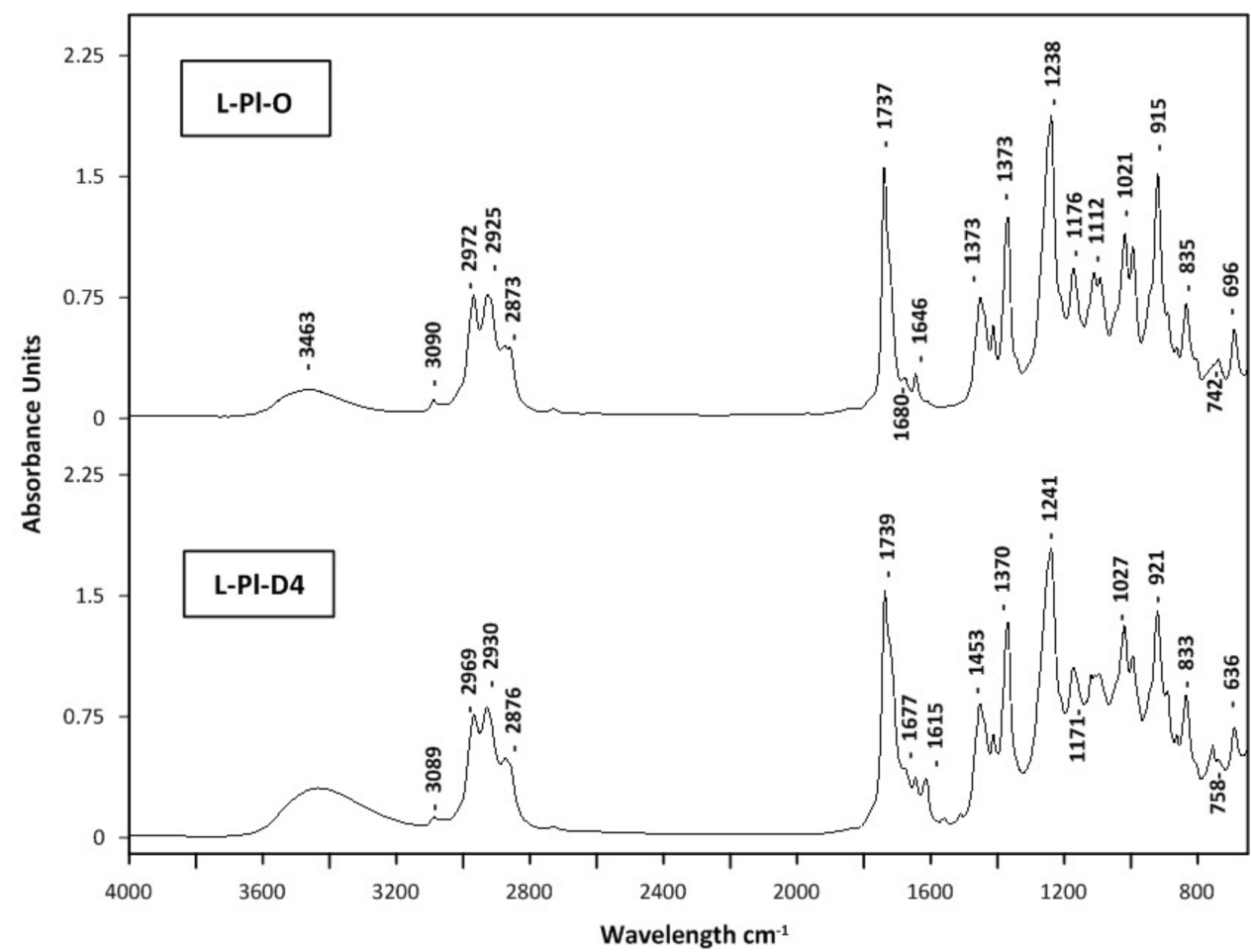

Figure 7. MIR spectra of lavender oil fractions; L-Pl-D4, L-Pl-O. 


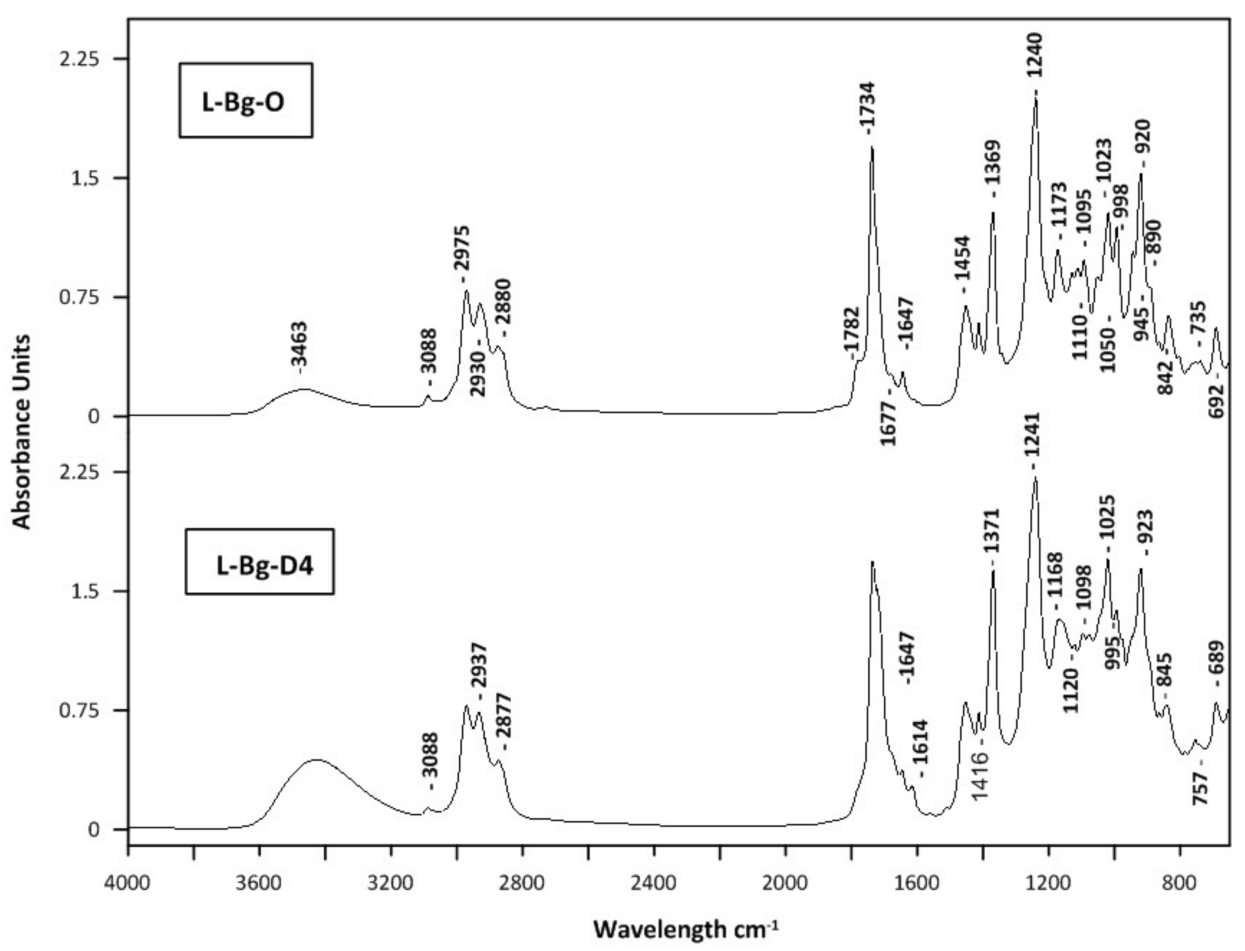

Figure 8. MIR spectra of lavender oil fractions; L-Bg-D4, L-Bg-O.

The application of HATR-FTIR enabled the analysis of selected fractions in the form of ultra-thin films with no additional pre-treatment. HATR-FTIR absorption spectra showed characteristic bands identified previously in lavender essential oils [58,59]. Since major components of lavender oils are linalyl acetate and linalool, FTIR spectra are dominated by vibrational modes from those monoterpenoids. The carbonyl groups $(\mathrm{C}=\mathrm{O})$ present in linalyl acetate and lavandulyl acetate were characterized by peaks at ca. $1735 \mathrm{~cm}^{-1}$. The corresponding band in L-Pl-D4 had a small shoulder with a maximum at $1680 \mathrm{~cm}^{-1}$, indicating the formation of a hydrogen bond between $\mathrm{C}=\mathrm{O}$ and $-\mathrm{OH}$ groups [57]. The area between 1100 and $1300 \mathrm{~cm}^{-1}$ included absorptions, representative for C-O stretching vibrations; those were documented at around $1239 \mathrm{~cm}^{-1}, 1171 \mathrm{~cm}^{-1}, 1112 \mathrm{~cm}^{-1}$, and $1110 \mathrm{~cm}^{-1}$, with some shifts in the $1176-1109 \mathrm{~cm}^{-1}$ region (Figures 7 and 8). The other characteristic vibrational frequencies for linalool and linalyl acetate were associated with the vinyl group vibration $\left(-\mathrm{C}=\mathrm{CH}_{2}\right)$; however, the intensity of a related peak around $1646 \mathrm{~cm}^{-1}$ is very weak. Additionally, the $-\mathrm{C}=\mathrm{CH}_{2}$ in-plane deformation vibration can be found at $1416 \mathrm{~cm}^{-1}$ as a weak band (Figures 7 and 8). The feature characteristic of the O-H stretching vibration of alcohol functional groups present in linalool, its derivatives: 8-hydroxylinalool, furanoid linalool oxides, 3,7-dimethyl-1,5-octadiene-3,7-diol (terpendiol I), and lavandulol, could be found as a broadband, in the region of $3400-3500 \mathrm{~cm}^{-1}$. Those bands were found to be some of the strongest affecting the principal components in the Lamiaceae family group essential oils on the basis of ATR-FTIR and PCA analysis [57]. In the spectra of lavender distillates, L-Pl-D4 and L-Bg-D4 (Figures 7 and 8), the signal of the O-H stretching mode was broad and more distinct compared to the spectra of corresponding light oils, which indicates hydrogen-bonding interactions between molecules. The differences in band positions, shapes, and intensities were also found in the area between 920 and $1240 \mathrm{~cm}^{-1}$ when comparing the spectra of lavender distillates and corresponding light oil fractions. The bonds, which have absorptions in the mentioned part of the fingerprint region, are those assigned to the $\mathrm{C}-\mathrm{O}$ stretching vibrations, $\mathrm{O}-\mathrm{C}-\mathrm{O}$ from primary alcohols (i.e., lavandulol) and $=\mathrm{C}-\mathrm{H}$ below $1000 \mathrm{~cm}^{-1}$. The bands at approximately $2800-3200 \mathrm{~cm}^{-1}$ may be related to $\mathrm{C}-\mathrm{H}$ stretching and $\mathrm{C}=\mathrm{C}-\mathrm{C}$ ring vibrations, both documented as absorbing around $2950 \mathrm{~cm}^{-1}$ [56]. Since the last mentioned vibrations are attributed to molecular fragments 
of linalyl acetate, linalool, and its derivatives (Figure 3), which are major constituents of the obtained lavender fractions, they would not impart significant changes in the FTIR spectra.

The GC-MS semi-quantitative characterization results of distillates L-Pl-D4 and L-BgD4, and the corresponding light oil fractions L-PL-O and L-Bg-O, which were collected in the cold trap, are reported in Table 6. These multicomponent mixtures are characterized by a few major compounds in higher contents (20-70\%). The major monoterpenoids of lavender fractions were linalool and linalyl acetate; however, there was a significant difference between the contents of each component when comparing fractions obtained from molecular distillations of L-Pl-E and L-Bg-E. The lowest linalool percentages were confirmed in L-Bg-D4 (7.58\%) and L-Bg-O (17.44\%), and, at the same time, the furanoid linalool oxides appeared in the highest content. The other late-eluting linalool derivatives/bioconversion products: 2,6-dimethyl-3,7-octadiene-2,6-diol, 2,6-dimethyl-1,7octadiene-3,6-diol, 8-hydroxylinalool, 6,7-epoxylinalool, 3,7-dimethyl-1,7-octadiene-3,6diol (terpendiol II) were found in higher amounts in L-Bg-D4 than in L-Pl-D4 (Figure 3, Table 6). Linalyl acetate was the most abundant component of the studied extracts, distillates, and light oil fractions; however, its percentage in distillate L-Bg-D4 was notably lower compared to L-Pl-D4 (Table 6). Since, in both distillates, physical refining caused a removal of heavy compounds, i.e., fatty acids and waxes, which diluted essential oil components in feedstocks, the late-eluting components remaining in L-Bg-D4 and L-Pl-D4 were coumarins, sesquiterpenes, and their derivatives (Figure 9). The identification of individual components using GC-MS and library spectra might not be reliable, particularly in the sesquiterpene region of the chromatogram where there were eluted, structurallyrelated components [60]. Some of the components eluted between 30 and 55 min (Figure 9) remained uncharacterized (Table 6). Nevertheless, according to a quantitative analysis by GC-FID, employing an external standard technique, caryophyllene oxide was quantified in both distillates, L-Pl-D4 and L-Bg-D4, at different levels, 34.75 and $13.80 \mathrm{mg} / \mathrm{g}$ (Table 6), respectively. Caryophyllene (and its oxidation product) was one of the few sesquiterpenes assigned in the light oil fractions (Table 6) using GC-MS.

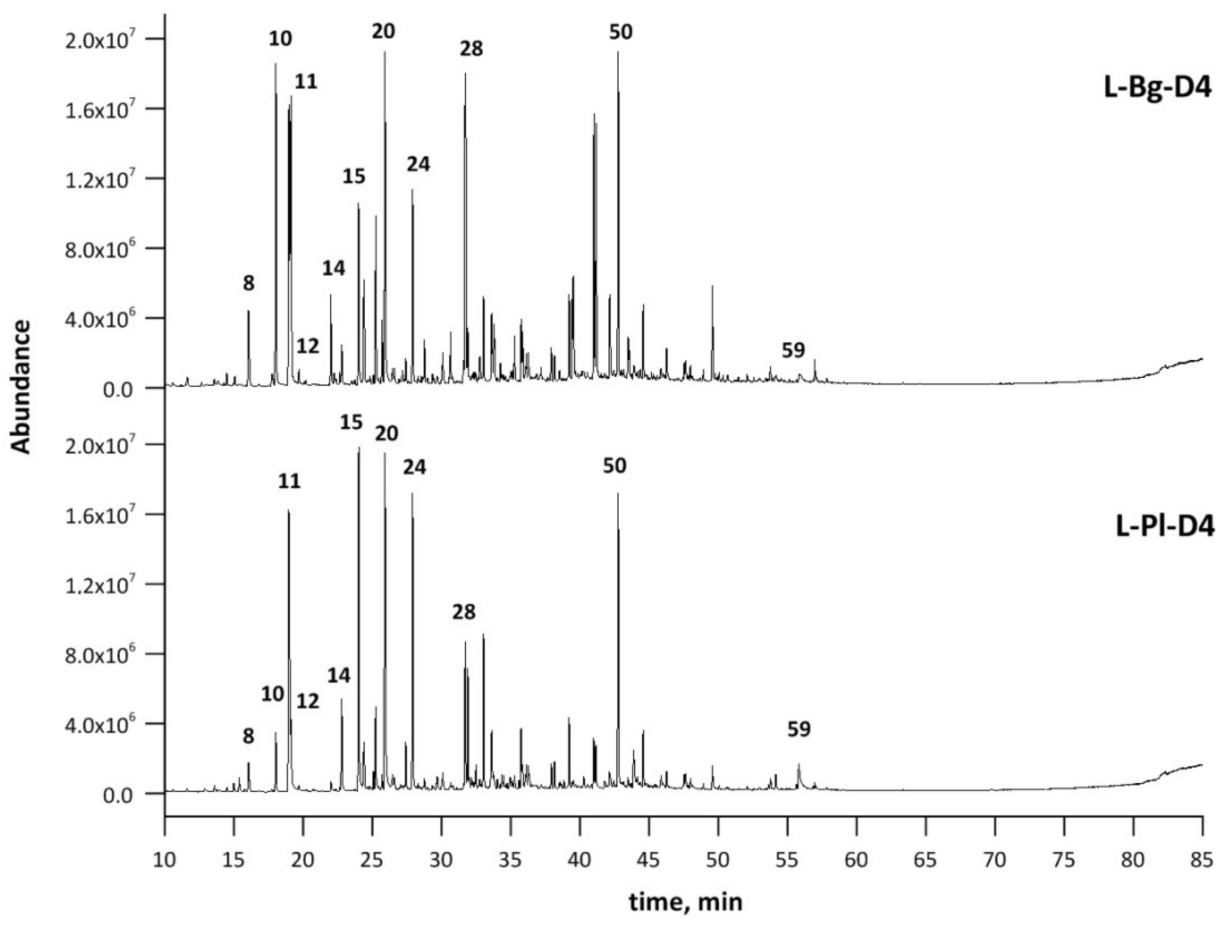

Figure 9. GC-MS chromatograms of L-Pl-D4 and L-Bg-D4 samples. Peaks in order of elution: 8) eucalyptol, 10) cis-furan linalool oxide, 11) linalool, 12) trans-furan linalool oxide, 14) lavandulol, 15) terpinen-4-ol, 20) linalyl acetate, 24) lavandulyl acetate, 28) 3,7-dimethyl-1,7-octadiene-3,6-diol (terpendiol II), 50) caryophyllene oxide, 59) herniarin. 
Table 6. The GC-MS chemical composition of distillates L-Pl-D4 and L-Bg-D4 and the corresponding light oils fractions, L-Pl-O and L-Bg-O.

\begin{tabular}{|c|c|c|c|c|c|c|c|}
\hline \multirow{2}{*}{ No. } & \multirow{2}{*}{ Compound } & \multirow{2}{*}{ RI } & \multirow{2}{*}{ RT } & \multicolumn{4}{|c|}{ Composition, $\%$} \\
\hline & & & & L-P1-D4 & L-Bg-D4 & L-Pl-O & L-Bg-O \\
\hline 1 & $\alpha$-Pinene & 1022 & 11.59 & - & - & 0.21 & 0.48 \\
\hline 2 & Camphene & 1075 & 13.52 & - & - & 0.30 & 0.22 \\
\hline 3 & $(-)-\beta$-Pinene & 1082 & 13.81 & - & - & 0.36 & 0.17 \\
\hline 4 & 1-Octen-3-ol & 1095 & 14.43 & - & 0.20 & 0.38 & 0.53 \\
\hline 5 & 3-Octanone & 1101 & 15.02 & - & - & 0.39 & 0.42 \\
\hline 6 & (-)-Limonene & 1113 & 14.98 & - & - & 0.73 & - \\
\hline 7 & trans- $\beta$-Ocimene & 1123 & 15.38 & 0.26 & - & 1.06 & - \\
\hline 8 & Eucalyptol & 1139 & 16.05 & 0.84 & 1.80 & 3.27 & 4.23 \\
\hline 9 & Sabinene hydrate & 1179 & 17.69 & - & - & - & 0.27 \\
\hline 10 & cis-Linalool oxide (furanoid) & 1186 & 18.03 & 1.19 & 5.54 & 2.61 & 10.72 \\
\hline 11 & Linalool (3,7-dimethyl-1,6-octadien-3-ol) & 1209 & 18.98 & 19.21 & 8.38 & 28.34 & 17.44 \\
\hline 12 & trans-Linalool oxide (furanoid) & 1212 & 19.13 & 1.20 & 4.89 & 2.57 & 9.21 \\
\hline 13 & Lavender lactone & 1278 & 22.01 & - & 1.32 & 0.41 & 2.49 \\
\hline 14 & Lavandulol & 1295 & 22.78 & 1.84 & 0.71 & 1.52 & 0.87 \\
\hline 15 & Terpinen-4-ol & 1323 & 24.01 & 7.17 & 3.06 & 7.56 & 4.20 \\
\hline 16 & Linalool oxide (pyranoid) & 1332 & 24.40 & 1.05 & 2.33 & 1.42 & 2.87 \\
\hline 17 & $\alpha$-Terpineol & 1348 & 25.09 & 0.31 & - & 0.19 & - \\
\hline 18 & 2,6-Dimethyl-3,7-octadiene-2,6-diol & 1352 & 25.24 & 1.41 & 2.64 & - & - \\
\hline 19 & $\begin{array}{l}\text { 3,7-Dimethyl-1,5- octadiene-3,7-diol } \\
\text { (terpendiol I) }\end{array}$ & 1362 & 25.70 & 0.26 & 0.92 & - & 0.87 \\
\hline 20 & Linalool acetate & 1368 & 25.94 & 30.51 & 20.84 & 36.42 & 32.34 \\
\hline 21 & NI & 1380 & 26.46 & 0.31 & - & - & 0.21 \\
\hline 22 & Isobornyl formate & 1392 & 26.52 & - & - & 0.29 & - \\
\hline 23 & Crypton & 1402 & 27.42 & 0.80 & - & 1.07 & 0.55 \\
\hline 24 & $( \pm)$-Lavandulyl acetate & 1413 & 27.91 & 5.17 & 3.02 & 4.50 & 3.99 \\
\hline 25 & Bornyl acetate & 1433 & 28.76 & - & 0.66 & 0.22 & 1.03 \\
\hline 26 & $p$-Cumic aldehyde & 1456 & 29.69 & 0.29 & - & 0.36 & 0.21 \\
\hline 27 & 2,6-Dimethyl-1,7-octadiene-3,6-diol & 1465 & 30.08 & 0.48 & 0.65 & - & - \\
\hline 28 & $\begin{array}{l}\text { 3,7-Dimethyl-1,7-octadien-3,6-diol, } \\
\text { (terpendiol II) }\end{array}$ & 1504 & 31.71 & 2.63 & 8.87 & - & 0.69 \\
\hline 29 & Longicyclene & 1508 & 31.90 & 2.05 & 1.00 & 1.66 & 1.02 \\
\hline 30 & $\alpha$-Bergamotene & 1523 & 32.49 & 0.33 & - & 0.25 & - \\
\hline 31 & $\beta$-Caryophyllene & 1537 & 33.04 & 2.68 & 1.33 & 2.73 & 1.69 \\
\hline 32 & $\beta$-Farnesene & 1551 & 33.62 & 1.49 & 1.41 & 0.19 & 0.59 \\
\hline 33 & $\begin{array}{l}\text { 2,6-Dimethyl-2,7-octadiene-1,6-diol } \\
\text { (8-hydroxylinalool) }\end{array}$ & 1555 & 33.78 & 0.29 & 1.17 & - & - \\
\hline 34 & Limonene-1,2-diol & 1569 & 34.36 & 0.22 & - & - & - \\
\hline 35 & Car-3-en-5-one & 1573 & 34.49 & 0.25 & - & - & - \\
\hline 36 & Nerolidol & 1592 & 35.28 & 0.25 & 0.60 & - & - \\
\hline 37 & cis-2-Methyl-3-oxo- cyclohexanebutanal & 1604 & 35.75 & 1.18 & 0.99 & - & - \\
\hline 38 & cis-9-Tetradecen-1-ol & 1607 & 35.86 & 0.39 & 0.81 & - & - \\
\hline 39 & Epoxylinalool & 1614 & 36.13 & 0.35 & - & - & - \\
\hline 40 & Farnesyl formate & 1618 & 36.28 & 0.55 & 0.50 & - & - \\
\hline 41 & Nerolidyl acetate & 1661 & 37.93 & 0.43 & 0.54 & - & - \\
\hline 42 & $\alpha$-Santalol & 1667 & 38.17 & 0.49 & - & - & - \\
\hline 43 & $\alpha$-Bisabolol & 1694 & 39.21 & 1.18 & 1.24 & - & - \\
\hline 44 & NI & 1705 & 39.46 & - & 1.46 & - & - \\
\hline 45 & NI & 1716 & 39.54 & - & 1.51 & - & - \\
\hline 46 & Ascaridole & 1723 & 40.28 & 0.24 & 0.24 & - & - \\
\hline 47 & NI & 1743 & 41.00 & 0.95 & 4.11 & - & - \\
\hline 48 & NI & 1747 & 41.15 & 0.54 & 3.75 & - & - \\
\hline 49 & $(1 S, 2 S, 4 S)$-Trihydroxy- $p$-menthane & 1774 & 42.13 & 0.45 & 1.53 & - & - \\
\hline 50 & $\beta$-Caryophyllene oxide & 1791 & 42.77 & 5.63 & 5.30 & 0.98 & 1.27 \\
\hline
\end{tabular}


Table 6. Cont.

\begin{tabular}{|c|c|c|c|c|c|c|c|}
\hline \multirow{2}{*}{ No. } & \multirow{2}{*}{ Compound } & \multirow{2}{*}{ RI } & \multirow{2}{*}{ RT } & \multicolumn{4}{|c|}{ Composition, $\%$} \\
\hline & & & & L-P1-D4 & L-Bg-D4 & L-P1-O & L-Bg-O \\
\hline 51 & NI & 1811 & 43.47 & - & 0.82 & - & - \\
\hline 52 & Coumarin & 1823 & 43.88 & 1.10 & - & - & - \\
\hline 53 & tau-Cadinol & 1842 & 44.57 & 0.94 & 1.07 & - & - \\
\hline 54 & Longifolene aldehyde & 1880 & 45.87 & 0.30 & - & - & - \\
\hline 55 & Ledene oxide-(II) & 1891 & 46.27 & 0.31 & 0.60 & - & - \\
\hline 56 & Isolongifolol & 1990 & 49.57 & 0.46 & 1.41 & - & - \\
\hline 57 & Neryl acetate & 2121 & 53.76 & 0.25 & 0.24 & - & - \\
\hline 58 & Gerany-p-cymene & 2134 & 54.16 & 0.29 & - & - & - \\
\hline 59 & Herniarin & 2189 & 55.82 & 1.38 & 0.55 & - & - \\
\hline
\end{tabular}

\subsection{Antimicrobial Activity}

This is the first report to study MD fractions in terms of antimicrobial activities. As presented in Table 7, the distillates (L-Pl-D4, L-Bg-D4) and the related cold trap light oil fractions (L-Pl-O and L-Bg-O) isolated from two lavender $\mathrm{scCO}_{2}$ extracts showed antibacterial activity. Gram-positive bacteria were more susceptible to both distillates and light oils according to the minimum inhibitory concentration (MIC) (MIC $=0.5-4 \mathrm{mg} / \mathrm{mL}$ ) when compared with E. coli, being Gram-negative bacterium (MIC $=8 \mathrm{mg} / \mathrm{mL}$ ). The yeast strains were more susceptible to the distillates and light oils (MIC $=0.5-1 \mathrm{mg} / \mathrm{mL}$ ) than the most bacterial strains. There were some differences between the antimicrobial activities of distillates (L-Pl-D4 and L-Bg-D4) and the corresponding light oil fractions. Predoi et al. [61] reported MIC and MBC values of $<0.1$ for essential oil hydrodistilled from L. angustifolia. However, the studied L. angustifolia hydro-distillated from southern Romania was characterized by a higher content of linalool $(47.75 \%)$ when compared with L-Pl-D4 (19.79\%) and L-Bg-D4 (7.58\%).

Table 7. Antimicrobial activity of distillates D4 and light oil fractions resulting from MD of lavender $\mathrm{scCO}_{2}$ extracts as well as crude extracts assessed as MIC, MBC, or MFC.

\begin{tabular}{|c|c|c|c|c|c|c|c|c|c|c|c|c|}
\hline \multirow{2}{*}{$\begin{array}{c}\text { Microorganisms } \\
\text { Gram-positive bacteria }\end{array}$} & \multicolumn{2}{|c|}{ L-Pl-D4 } & \multicolumn{2}{|c|}{ L-P1-O } & \multicolumn{2}{|c|}{ L-Bg-D4 } & \multicolumn{2}{|c|}{ L-Bg-O } & \multicolumn{2}{|c|}{ L-Pl-E } & \multicolumn{2}{|c|}{ L-Bg-E } \\
\hline & MIC & $\mathrm{MBC}$ & MIC & $\mathrm{MBC}$ & MIC & $\mathrm{MBC}$ & MIC & $\mathrm{MBC}$ & MIC & $\mathrm{MBC}$ & MIC & MBC \\
\hline $\begin{array}{c}\text { Staphylococcus aureus ATCC } \\
25923\end{array}$ & 1 & 2 & 2 & 4 & 2 & 2 & 4 & 8 & 2 & 4 & 2 & 4 \\
\hline $\begin{array}{c}\text { Staphylococcus aureus ATCC } \\
29213\end{array}$ & 2 & 4 & 4 & 8 & 4 & 4 & 4 & 8 & 4 & 8 & 8 & 8 \\
\hline $\begin{array}{c}\text { Staphylococcus aureus ATCC } \\
\text { BAA } 1707\end{array}$ & 2 & 4 & 4 & 8 & 4 & 8 & 4 & 8 & 2 & 8 & 4 & 8 \\
\hline Bacillus subtilis ATCC 6633 & 2 & 2 & 1 & 4 & 1 & 4 & 2 & 4 & 0.25 & 4 & 0.06 & 4 \\
\hline Bacillus cereus ATCC 10876 & 2 & 2 & 4 & 4 & 2 & 2 & 4 & 4 & 1 & 16 & 2 & 16 \\
\hline Micrococcus luteus ATCC 10240 & 0.5 & 2 & 1 & 4 & 1 & 2 & 1 & 4 & 0.5 & 4 & 0.5 & 4 \\
\hline Micrococcus faecalis ATCC 29212 & 1 & 4 & 1 & 4 & 2 & 8 & 2 & 8 & 1 & 16 & 4 & 16 \\
\hline Gram-negative bacteria & MIC & MBC & $\mathrm{MIC}$ & $\mathrm{MBC}$ & MIC & $\mathrm{MBC}$ & $\mathrm{MIC}$ & $\mathrm{MBC}$ & $\mathrm{MIC}$ & MBC & $\mathrm{MIC}$ & $\mathrm{MBC}$ \\
\hline Escherichia coli ATCC 25922 & 8 & 8 & 8 & 8 & 8 & 16 & 8 & 16 & 8 & 16 & 16 & 16 \\
\hline Yeast strains & MIC & MFC & MIC & MFC & MIC & MFC & $\mathrm{MIC}$ & MFC & MIC & MFC & MIC & MFC \\
\hline Candida albicans ATCC 10231 & 0.5 & 1 & 0.5 & 1 & 0.5 & 1 & 0.5 & 1 & 2 & 4 & 4 & 4 \\
\hline Candida glabrata ATCC 90030 & 1 & 2 & 1 & 2 & 1 & 2 & 1 & 2 & 2 & 4 & 4 & 8 \\
\hline Candida krusei ATCC 14243 & 1 & 1 & 1 & 1 & 1 & 2 & 1 & 2 & 2 & 4 & 4 & 8 \\
\hline
\end{tabular}

$\mathrm{MIC}, \mathrm{MBC}$, and MFC were expressed as $\mathrm{mg} / \mathrm{mL}$. The representative data (mode) are presented. 
Subsequently, the activity of the $\mathrm{scCO}_{2}$ crude extracts from lavender (L-Pl-E and L$\mathrm{Bg}-\mathrm{E}$ ) against bacteria and yeasts was also examined. Gram-positive bacteria were found to be more-or-less susceptible to both extracts as compared to the distillates and light oils, depending on the bacterial species. The highest activity of both extracts was observed against Bacillus subtilis ATCC 6633 with MIC $=0.25 \mathrm{mg} / \mathrm{mL}$ (L-Pl-E) and MIC $=0.06 \mathrm{mg} / \mathrm{mL}$ (L-Bg-E). Candida spp. showed lower susceptibility to both extracts (MIC $=2-4 \mathrm{mg} / \mathrm{mL}$ ) than to distillates and light oils.

It was found that all studied fractions (distillates and light oils) possessed bactericidal and fungicidal effects, confirmed by MBC minimum bactericidal concentration/MIC = 1-4 and minimum fungicidal concentration $(\mathrm{MFC}) / \mathrm{MIC}=1-2$. It is generally accepted that antimicrobials are usually regarded as bactericidal or fungicidal if the $\mathrm{MBC} / \mathrm{MIC}$ or $\mathrm{MFC} / \mathrm{MIC}$ ratio is $\leq 4$ [62]. However, it should be noted that the crude lavender extracts had bactericidal $(\mathrm{MBC} / \mathrm{MIC}=1-4)$ or bacteriostatic effects $(\mathrm{MBC} / \mathrm{MIC}=4-16)$, depending on the bacteria species, while both extracts exerted fungicidal effects (MFC/MIC $=1-2$ ).

The reference substances, such as coumarin, herniarin (7-methoxycoumarin), linalool, linalyl acetate, caryophyllene oxide, lavandulol, and lavandulyl acetate were also used for antibacterial and antifungal activity tests (Table 8). Generally, lavandulol and lavandulyl acetate were mostly active against Gram-positive bacteria, with yeasts $\mathrm{MIC} \leq 0.5 \mathrm{mg} / \mathrm{mL}$ showing the widest spectrum of activity. B. subtilis ATCC 6633 and M. luteus ATCC 10240 were found susceptible to all compounds included. They had bactericidal (MBC/MIC = 1-4) or bacteriostatic effects ( $\mathrm{MBC} / \mathrm{MIC}=8-128)$, depending on the bacteria species, while all exerted fungicidal effects (MFC/MIC $=1-4)$.

Table 8. Antimicrobial activity of the selected compounds identified in Lavandula angustifolia Mill. assessed as MIC, MBC, or MFC.

\begin{tabular}{|c|c|c|c|c|c|c|c|c|c|c|c|c|c|c|}
\hline \multirow{2}{*}{$\begin{array}{c}\text { Microorganisms } \\
\text { Gram-positive bacteria }\end{array}$} & \multicolumn{2}{|c|}{$\mathbf{A}$} & \multicolumn{2}{|c|}{ B } & \multicolumn{2}{|c|}{ C } & \multicolumn{2}{|c|}{ D } & \multicolumn{2}{|c|}{ E } & \multicolumn{2}{|c|}{$\mathbf{F}$} & \multicolumn{2}{|c|}{ G } \\
\hline & MIC & MBC & MIC & $\mathrm{MBC}$ & MIC & MBC & MIC & MBC & MIC & $\mathrm{MBC}$ & MIC & $\mathrm{MBC}$ & MIC & $\mathrm{MBC}$ \\
\hline $\begin{array}{c}\text { Staphylococcus aureus ATCC } \\
25923\end{array}$ & 1 & 2 & 1 & 1 & 2 & 4 & 2 & 2 & 1 & 4 & 0.5 & 1 & 0.5 & 1 \\
\hline $\begin{array}{c}\text { Staphylococcus aureus ATCC } \\
29213\end{array}$ & 0.25 & 4 & 2 & 4 & 2 & 4 & 2 & 2 & 1 & 2 & 0.5 & 1 & 1 & 2 \\
\hline $\begin{array}{c}\text { Staphylococcus aureus ATCC } \\
\text { BAA1707 }\end{array}$ & 0.25 & 4 & 2 & 4 & 2 & 4 & 2 & 4 & 1 & 4 & 0.5 & 1 & 1 & 2 \\
\hline Bacillus subtilis ATCC 6633 & 1 & 4 & 0.125 & 2 & 0.5 & 2 & 2 & 2 & 0.5 & 4 & 0.06 & 0.5 & 0.06 & 2 \\
\hline Bacillus cereus ATCC 10876 & 1 & 4 & 0.25 & 4 & 2 & 4 & 2 & 4 & 1 & 4 & 0.5 & 4 & 1 & 4 \\
\hline Micrococcus luteus ATCC 10240 & 0.5 & 2 & 0.5 & 4 & 0.25 & 1 & 0.5 & 2 & 0.03 & 4 & 0.125 & 1 & 0.125 & 1 \\
\hline Micrococcus faecalis ATCC 29212 & 1 & 4 & 2 & 4 & 1 & 4 & 0.5 & 2 & 0.5 & 4 & 0.5 & 2 & 2 & 8 \\
\hline Gram-negative bacteria & MIC & $\mathrm{MBC}$ & MIC & $\mathrm{MBC}$ & MIC & $\mathrm{MBC}$ & MIC & $\mathrm{MBC}$ & MIC & $\mathrm{MBC}$ & MIC & $\mathrm{MBC}$ & MIC & $\mathrm{MBC}$ \\
\hline Escherichia coli ATCC 25922 & 2 & 4 & 0.5 & 4 & 1 & 4 & 2 & 4 & 2 & 4 & 1 & 1 & 1 & 2 \\
\hline Yeast strains & MIC & MFC & MIC & MFC & MIC & MFC & MIC & MFC & MIC & MFC & MIC & MFC & MIC & MFC \\
\hline Candida albicans ATCC 10231 & 1 & 2 & 0.5 & 1 & 1 & 1 & 0.5 & 1 & 0.5 & 2 & 0.5 & 0.5 & 0.5 & 1 \\
\hline Candida glabrata ATCC 90030 & 1 & 2 & 0.5 & 1 & 1 & 1 & 1 & 2 & 0.5 & 2 & 0.5 & 0.5 & 0.5 & 1 \\
\hline Candida krusei ATCC 14243 & 1 & 4 & 1 & 2 & 1 & 1 & 1 & 2 & 1 & 2 & 0.5 & 0.5 & 0.25 & 1 \\
\hline
\end{tabular}

\section{Discussion}

Lavandula angustifolia Mill. is a known source of essential oil (Oleum Lavandulae) with well-defined biological, antimicrobial, and therapeutic properties. Hence, there is a strong demand for high quality lavender products, desirable not only by the fragrance and 
perfume industries, but also in skincare and beauty products, pharmaceutical products, and in other forms of integrative medicine. According to Moussi Imane et al. [63] and Ciocarlan et al. [64], L. angustifolia essential oil demonstrates good activity against several bacterial species.

The essential oil of L. angustifolia, which is commonly produced through steam distillation or hydrodistillation as its variant, is one of the most extensively studied essential oils in terms of its antimicrobial activities $[4,6,8,38,59,65]$. Linalool and linalyl acetate are predominant lavender essential oil oxygenated monoterpenes (about $70 \%$ of the total composition) and their biological activities (e.g., anti-inflammatory [66], antibacterial [67,68], and antifungal [69]) have been evaluated individually. However, specific biological activities of the oil depend on the contributions of individual metabolites, classified as major and minor. Many scientific studies have compared different L. angustifolia essential oils, showing how strongly a geographic region of origin can influence the chemical composition of metabolites and, thus, contribute particular antimicrobial activities [65].

This study aimed to produce lavender fractions, rich in oxygenated monoterpenes from L. angustifolia supercritical extracts, using molecular distillation. Both SFE and MD techniques are gentle, free of toxic solvents, and could be used to design industrial processes. Recent applications of SFE coupled with MD have been developed mostly for enrichment of artemisia and turmeric $\mathrm{scCO}_{2}$ extracts in bioactive constituents of corresponding essential oils and further refinement of obtained extracts $[15,27,28]$. Although the SFE process of L. angustifolia performed under optimized conditions $[13,14]$ was found to be the most advantageous technology, in terms of high total extraction yield and high recovery of precious oxygenated monoterpenes, there is no available procedure that combines SFE and $\mathrm{MD}$, in regard to separating crucial lavender essential oil components from $\mathrm{scCO}_{2}$ extracts. Regarding the composition of lavender $\mathrm{scCO}_{2}$ extracts obtained from high density $\mathrm{scCO}_{2}$, they were characterized as mostly similar (closest) to starting the composition of the plant matter, with coumarins and fragrance molecules "fixed" with wax structures $[13,70]$.

In this research, two molecular distillations were performed for $\mathrm{scCO}_{2}$ extracts obtained from L. angustifolia cultivated in two European countries: Poland and Bulgaria. The variations of the extracted plant material, owing to the geographic source, made this study more challenging, in terms of MD parameters that had to be adjusted individually to each of the studied lavender $\mathrm{scCO}_{2}$ extracts. The differences between yellow-green extracts, L-Bg-E and L-Pl-E, were reflected mostly in the compositions of the waxy structures, which affected their melting properties and fluidity. The different physicochemical properties of L-Bg-E and its "congelation" tendency over distillation times required maintaining higher wiper basket speeds, higher temperatures of the feed tanks and residue discharge, compared to processing parameters during distillation of L-Pl-E. However, both purification procedures were evaluated through five experiments according to the influence of the evaporator temperature increasing stepwise from $55^{\circ} \mathrm{C}$ to $95^{\circ} \mathrm{C}$, with an interval of $10^{\circ} \mathrm{C}$. Monoterpenoids, coumarins, and caryophyllene oxide contents in distillates (D1-D5) and corresponding feedstreams (L-Bg-E and L-Pl-E) were analyzed quantitatively. The amount of material (light oil and water) collected in the cold trap glass cover (vacuum pump system guard) was also controlled after each experiment. The best results for high-quality distillates and process conditions ensuring efficient mass and heat transfer during molecular distillation of both lavender extracts were obtained at an EVT of $85^{\circ} \mathrm{C}$. In both distillates, L-Bg-D4 and L-Pl-D4, it was confirmed that the contents of the selected monoterpenoids, including crucial lavender fragrance ingredients, i.e., linalyl acetate, linalool, and lavandulyl acetate increased twice compared to corresponding starting crude extracts. This is due to removal of higher boiling waxy components. Moreover, distillates contain coumarins and their contents are at similar levels in L-Bg-D4 and L-Pl-D4, although, in the corresponding extracts, their amounts are higher. The light oil fractions (L-Bg-O and L-Pl-O) are abundant with target monoterpenoids, linalool derivatives, and some sesquiterpenes, while caryophyllene oxide is the highest boiling component of the fraction. Vibrational modes 
from major monoterpenoids dominated FTIR spectra, which additionally confirmed good quality of the distillates.

Selected distillates (L-Bg-D4 and L-Pl-D4), as well as standard reference materials (separate compounds), were also evaluated for their antimicrobial properties by determining the minimum inhibitory concentration (MIC) by the broth microdilution method. The antibacterial and antifungal activities of L. angustifolia Mill. can be explained by the presence of such components as linalool, linalyl acetate, lavandulol, geraniol, and eucalyptol [8]. In the present study, lavandulol and lavandulyl acetate were found to be active mostly against Gram-positive bacteria and yeasts with MIC $\leq 0.5 \mathrm{mg} / \mathrm{mL}$. These compounds showed the widest spectrums of activity among the components included in the present study, also identified elsewhere in L. angustifolia Mill. [37]. All included reference substances had bactericidal $(\mathrm{MBC} / \mathrm{MIC}=1-4)$ and fungicidal effects $(\mathrm{MFC} / \mathrm{MIC}=1-4)$.

The light oils, similar to distillates, collected as cold trap fractions (L-Pl-O and L-Bg-O) during molecular distillations at $85^{\circ} \mathrm{C}$, were also studied for their antimicrobial properties. The light oil fractions ( $\mathrm{L}-\mathrm{Bg}-\mathrm{O}$ and $\mathrm{L}-\mathrm{Pl}-\mathrm{O}$ ) are abundant with target monoterpenoids, linalool derivatives, and some sesquiterpenes, while caryophyllene oxide is the highest boiling component of the fraction. Regarding antimicrobial activity of the distillates (L-PlD4, L-Bg-D4) and their related light oils (L-Pl-O, L-Bg-O), it should be noted that, generally, distillates proved to be somewhat more active than light oils, most probably due to their multicomponent nature (sesquiterpenoids and coumarins). However, the higher amount of linalool and linalyl acetate was still responsible for inhibitory effects against several bacterial species [71]. Distillates and oils exerted biocidal effects against bacteria and fungi (yeasts), and even higher susceptibility of Candida spp. to both distillates and light oils than to the crude extracts observed. The extracts revealed the highest activity against $B$. subtilis ATCC 6633 compared to other tested reference strains. L-Bg-E was more active $(\mathrm{MIC}=0.06 \mathrm{mg} / \mathrm{mL})$ compared to L-Pl-E (MIC $=0.25 \mathrm{mg} / \mathrm{mL}$ ).

The presented data indicate the $\mathrm{scCO}_{2}$ extracts from L. angustifolia cultivated in Poland and Bulgaria as well as the corresponding fractions (distillates, light oils) may be regarded as a source of the valuable components with antimicrobial activity.

It was reported that biological activity of Lavandula species, including L. angustifolia Mill., depends on several factors, including the extraction procedure [72,73]. Recently, Garzoli et al. [74] studied the activity of essential oils and hydrolates from L. angustifolia Mill. grown in Italy against both Gram-positive (Bacillus cereus) and Gram-negative bacteria (Escherichia coli, Acinetobacter bohemicus, Pseudomonas fluorescens). Essential oils were found to possess high antibacterial activities with MICs ranging from 0.19 to $1.56 \%(v / v)$, in comparison, hydrolates did not show any inhibition of the bacterial growth at the tested concentrations due to the presence of only some volatile oil compounds.

\section{Materials and Methods}

\subsection{Chemical and Reagents}

Food grade $\mathrm{CO}_{2} \geq 99.90 \%$ (Zakłady Azotowe Puławy S.A., Puławy, Poland) was applied to SFE. All solvents (dichloromethane and methanol) were of analytical grade and were purchased from J.T. Baker (Center Valley, PA, USA). The certified reference material, C7-C40 saturated n-alkanes (1000 $\mu \mathrm{g} / \mathrm{mL}$ each component in hexane) were obtained from Supelco (Poznan, Poland). Linalyl acetate $(\geq 97.0 \%)$, linalool $(\geq 99.0 \%)$, caryophyllene oxide ( $\geq 99.0 \%)$, $\alpha$-terpineol ( $\geq 98.5 \%$ ), eucalyptol ( $\geq 99.0 \%)$, terpinen-4-ol, (primary reference standard), lavandulol (analytical standard), lavandulol acetate (analytical standard), coumarin (primary analytical standard), 7-methoxycoumarin (primary reference standard) were supplied by Merck (Poland). Carnauba and beeswax were purchased from ECOSPA (Warsaw, Poland).

\subsection{Plants Materials}

Lavender (Lavandula angustifolia Mill.) cultivars of Polish and Bulgarian origin were used in this study. Dry lavender flowers (L-Pl) and (L-Bg) were delivered by GRUPA INCO 
Company (Góra Kalwaria, Poland). Both raw materials were ground using a Retsch mill (SM100), sieved to $1 \mathrm{~mm}$ and subjected to SFE.

\subsection{Supercritical Fluid Extraction}

A pilot scale supercritical fluid extraction (SFE) with carbon dioxide was performed on a $40 \mathrm{~L}$ volume extractor (ELAB, Puławy, Poland) at the temperature of $40^{\circ} \mathrm{C}$, under the pressure of $30 \mathrm{Mpa}$, and the extraction time was $2 \mathrm{~h}$. The $\mathrm{CO}_{2}$ consumption was $32.86 \mathrm{kgCO}_{2} / \mathrm{kg}$ batch. The SFE resulted in a higher extraction yield $(7.05 \mathrm{wt} \%)$ for L-Pl $\mathrm{scCO}_{2}$ extract compared to $\mathrm{L}-\mathrm{Bg} \mathrm{scCO}_{2}$ extract $(6.33 \mathrm{wt} \%)$.

\subsection{Molecular Distillation}

A laboratory short-path distillation (SPD) system KDL-5 (UIC GmbH, Alzenau, Germany) was used to perform the molecular distillation of lavender $\mathrm{scCO}_{2}$ extracts. The wiped film molecular distillation model KDL 5 is a variation of falling film molecular distillation with agitation. The basic design of the wiped film variation of the (short path) distillation unit was a vertical double-jacketed cylindrical evaporator $\left(4.8 \mathrm{dm}^{2}\right)$ with a cooled internal condenser $\left(6.5 \mathrm{dm}^{2}\right)$ concentrically situated inside the cylinder. The evaporator surface $\left(4.8 \mathrm{dm}^{2}\right)$, residue, and distillate sections were individually heatable with heating oil. The feed rate was continuously adjustable between 0 and $1.8 \mathrm{~L} / \mathrm{h}$. Due to the compact design of the feed system (heatable feed gear pump system with drive motor, double jacketed product feed vessel, roller wiper system with drive motor, and continuously adjustable speed), the areas between feed vessel and evaporator were heatable. For the optimal product distribution, the feed product was pumped on top of the rotating wiper basket plate (continuously adjustable sped from 200 to $500 \mathrm{rpm}$ ) to be wiped with rollers in the form of thin film falling down the surface of the glass evaporator. The glass cold trap $\left(-80^{\circ} \mathrm{C}\right)$ with an immersion cooling finger made of stainless steel was a part of the vacuum configuration and was used to trap and retain volatile molecules from the process to avoid pump oil contamination. The vacuum system was a set consisting of a rotary vane pump and an oil diffusion pump, put in series. Distillations were carried out at pressures around $1 \mathrm{~Pa}$ and were measured electronically by the Pirani style vacuum sensor.

\subsection{Chemical Analysis}

\subsubsection{Gas Chromatography Equipped with Tandem Mass Spectrometry (GC-MS/MS)}

The identification and determination of the extract components were performed with an Agilent (Santa Clara, CA, USA) 7000 QQQ system (7890 gas chromatograph combined with triple-quadrupole MS with an electron ionization (EI) source). The capillary column DB-EUPAH UI $(60 \mathrm{~m} \times 0.25 \mathrm{~mm}$ i.d. $\times 0.25 \mu \mathrm{m})$ with helium $(99.9999 \%)$ as a carrier gas at a flow rate of $0.6 \mathrm{~mL} / \mathrm{min}$ was applied. Data acquisition was performed in the scan mode. The oven temperature was set to $60^{\circ} \mathrm{C}$ at the starting point, and then gradually increased from $60^{\circ} \mathrm{C}$ to $310^{\circ} \mathrm{C}$ at $3{ }^{\circ} \mathrm{C} / \mathrm{min}$ with a final hold of $3 \mathrm{~min}$. Mass spectra were taken at $70 \mathrm{eV}$ and the mass range $(\mathrm{m} / \mathrm{z})$ was 35-650. Identification of the components was carried out using MassHunter software (C.01.03), NIST Mass Spectral Library, and MS literature data. Retention indices (RIs) of the compounds were determined, relative to the retention times of a standard solution of n-alkanes for GC (C8-C20 and C21-C40). The relative percentage of the individual components was calculated based on the GC peak areas without the use of correction factors.

\subsubsection{Gas Chromatography Equipped with Flame Ionization Detection (GC-FID)}

The quantitative analysis of the main fragrance components enriched in $\mathrm{scCO}_{2}$ extracts and distillate fractions (1,8-cineole, linalool, linalyl acetate, terpinen-4-ol, lavandulyl acetate, lavandulol, caryophyllene oxide) was performed by a capillary GC using a dual-channel Agilent 7820A GC system coupled with a flame ionization detector (FID). The volatiles were analyzed using the HP-5 column $(30 \mathrm{~m} \times 0.25 \mathrm{~mm} \times 0.20 \mu \mathrm{m})$. The FID detector temperature was set at $300{ }^{\circ} \mathrm{C}$ and injector temperature was set at $250{ }^{\circ} \mathrm{C}$. The oven 
temperature was programmed as follows: initial temperature $50{ }^{\circ} \mathrm{C}$, raised to $260{ }^{\circ} \mathrm{C}$ $\left(8{ }^{\circ} \mathrm{C} / \mathrm{min}\right)$. and held at $260{ }^{\circ} \mathrm{C}$ for $5 \mathrm{~min}$. High-purity helium (xx\%) was the carrier and made-up gas with the flow rate of 1.6 and $25 \mathrm{~mL} / \mathrm{min}$, respectively. The flow relation for the FID detector was $30.0 \mathrm{~mL} / \mathrm{min}$ for hydrogen and $400.0 \mathrm{~mL} / \mathrm{min}$ for air. The injection of all samples $(1 \mu \mathrm{L})$ was performed in a split mode (100:1) with a purge time of $0.75 \mathrm{~min}$. An HP ChemStation ver. C.01.03, (Agilent, Santa Clara, CA, USA) was used for an instrument control and data analysis. The total analysis time was $27.25 \mathrm{~min}$.

Calibration curves were obtained by analyzing eight standard solutions, which resulted in satisfactory linearity with high values for correlation coefficient $\left(\mathrm{R}^{2}\right)$. The limit of detection (LOD) and limit of quantification (LOQ) were calculated as 3 and $10 \mathrm{SD} / a$, respectively, where SD is the standard deviation of the response and $a$ is the slope of the calibration curve. The LOD and LOQ were 0.040 and $0.147 \mathrm{mg} / \mathrm{mL}$ for 1,8 -cineole, 0.045 and 0.059 and $0.197 \mathrm{mg} / \mathrm{mL}$ for linalool, 0.058 and $0.194 \mathrm{mg} / \mathrm{mL}$ for linalyl acetate, 0.018 and $0.059 \mathrm{mg} / \mathrm{mL}$ for terpinen-4-ol, 0.134 and $0.445 \mathrm{mg} / \mathrm{mL}$ for lavandulyl acetate, 0.027 and $0.089 \mathrm{mg} / \mathrm{mL}$ for lavandulol, and 0.03 and $0.101 \mathrm{mg} / \mathrm{mL}$ for caryophyllene oxide, respectively. The solutions were prepared in dichloromethane.

\subsubsection{Supercritical Fluid Chromatography (SFC)}

The SFC was used for the determination of coumarin and herniarin directly in extracts and distillate fractions after dilution in dichloromethane and methanol $(1: 1 v / v)$ on an Ultra-performance Convergence Chromatography (UPC ${ }^{2}$, Waters) system, with the Acquity $\mathrm{UPC}^{2}$ Fluoro-Phenyl column $(3.0 \times 100 \mathrm{~mm} \times 1.7 \mu \mathrm{m})$ at $35^{\circ} \mathrm{C}$. The back pressure regulator set at $12.6 \mathrm{MPa}$ controlled the outlet column pressure. The isocratic elution with a binary system of $\mathrm{CO}_{2}$ and methanol $(98: 2, v / v)$ was used for compound separation. The analyses were performed with the $\mathrm{CO}_{2} / \mathrm{MeOH}$ flow rate of $2.0 \mathrm{~mL} / \mathrm{min}$, injection volume of $2 \mu \mathrm{L}$, and UV wavelength at $270 \mathrm{~nm}$ for coumarin and $310 \mathrm{~nm}$ for herniarin.

The quantifications of coumarin and herniarin in lavender extracts and distilled fractions were performed by an external calibration curve constructed with standard solutions (coumarin; $1.28 \mathrm{mg} / \mathrm{mL}$, herniarin; $1.20 \mathrm{mg} / \mathrm{mL}$ ) prepared in dichloromethane and methanol $(1: 1, v / v)$. Calibration curve points (from $0.032 \mathrm{mg} / \mathrm{mL}$ to $0.64 \mathrm{mg} / \mathrm{mL}$ and from 0.03 to $0.60 \mathrm{mg} / \mathrm{mL}$ ) were injected in triplicate. The results showed excellent linearity $(\mathrm{R}=0.999-1.000)$. The LOD values were $2.98 \mu \mathrm{g} / \mathrm{mL}$ for coumarin and $3.29 \mu \mathrm{g} / \mathrm{mL}$ for herniarin, whereas LOQ were 11.24 and $10.73 \mu \mathrm{g} / \mathrm{mL}$, respectively.

\subsection{Differential Scanning Calorimetry}

The thermal characteristics of the extract samples were measured on a TA Instruments Calorimeter, model DSC Q20. An indium (melting point $56.6^{\circ} \mathrm{C}$ ) was used as a standard for the equipment calibration. The extract sample $(1-3 \mathrm{mg})$ was weighed into a closed aluminum pan and analyzed under nitrogen $(50 \mathrm{~mL} / \mathrm{min})$ using a three-stage heating and cooling profile. The first heating from 20 to $150{ }^{\circ} \mathrm{C}$, to remove the sample thermal history, was followed by an isotherm (at $150{ }^{\circ} \mathrm{C}$ ) for $1 \mathrm{~min}$, and then cooling to $-50^{\circ} \mathrm{C}$, followed by the second isotherm for $1 \mathrm{~min}$ and second heating from $-50{ }^{\circ} \mathrm{C}$ to $150{ }^{\circ} \mathrm{C}(1 \mathrm{~min}$ isotherm at $150{ }^{\circ} \mathrm{C}$ ). All applied heating and cooling rates were $10^{\circ} \mathrm{C} / \mathrm{min}$. The melting point range was determined using the DSC curves of the second heating cycle.

\subsection{HATR-FTIR}

The Thermo Scientific Smart Multi-Bounce HATR (Horizontal Attenuated Total Reflectance), Nicolet iS50 spectrometer (Thermo Scientific, Waltham, MA, USA), was applied to obtain high quality spectra of molecular distillation fractions of lavender oils. OMNIC ${ }^{\circledR}$ software was used to acquire MIR spectra in absorbance mode with a wave range of $650-4000 \mathrm{~cm}^{-1}$. For each sample, 32 scans per sample were collected using spectral resolution of $4 \mathrm{~cm}^{-1}$. The crystal material was zinc selenide ( $\left.\mathrm{ZnSe}\right)$, with a 45 -degree incidence angle. After the crystal was cleaned and infrared background was collected, each oil sam- 
ple was poured onto the crystal and pressed to a thin film to cover the whole surface of the crystal.

\subsection{Antimicrobial Tests}

The assay of antibacterial and antifungal activity of the distillates and light oil fractions separated from the $\mathrm{scCO}_{2}$ extracts obtained from Lavandula angustifolia was performed by the broth microdilution method, according to European Committee on Antimicrobial Susceptibility Testing (EUCAST) recommendations [75]. The following reference strains were used in the study: Staphylococcus aureus ATCC 25923, Staphylococcus aureus ATCC 29213, Staphylococcus aureus ATCC BAA1707, Bacillus subtilis ATCC 6633, Bacillus cereus ATCC 10876, Micrococcus luteus ATCC 10240, Enterococcus faecalis ATCC 29212 (representatives of Gram-positive bacteria), Escherichia coli ATCC 25922 (representative of Gram-negative bacteria), Candida albicans ATCC 10231, Candida glabrata ATCC 90030, and Candida krusei ATCC 14243 (representatives of fungi belonging to yeast). All of the used microbial strains were first subcultured on Mueller-Hinton Agar (MHA) for bacteria or MHA with $2 \%$ glucose for fungi and incubated at $35^{\circ} \mathrm{C}$ for $24 \mathrm{~h}$. Microbial colonies were collected and suspended in sterile physiological saline to obtain inoculum of $0.5 \mathrm{McF}$ arland standard, corresponding to $1.5 \times 10^{8} \mathrm{CFU} / \mathrm{mL}$ (colony forming units) for bacteria and $5 \times 10^{6} \mathrm{CFU} / \mathrm{mL}$ for fungi. The distillates and light oils were dissolved in DMSO to obtain the final concentration of $100 \mathrm{mg} / \mathrm{mL}$.

The two-fold dilutions of distillates and light oils and extracts in Mueller-Hinton Broth (MHB) for bacteria or in RPMI with $2 \%$ glucose for fungi were prepared in 96 -well polystyrene plates to obtain final concentrations ranging from 0.004 to $16 \mathrm{mg} / \mathrm{mL}$. Next, $2 \mu \mathrm{L}$ of a particular bacterial or fungal inoculum was added to each well, containing $200 \mu \mathrm{L}$ of the serial dilution of distillates and light oils in the appropriate culture medium. After incubation at $35{ }^{\circ} \mathrm{C}$ for $24 \mathrm{~h}$, the MIC was assessed spectrophotometrically as the lowest concentrations of distillates and light oils showing complete bacterial or fungal growth inhibition. Appropriate DMSO, growth, and sterile controls were carried out. Coumarin, herniarin (7-methoxycoumarin), linalool, linalyl acetate, caryophyllene oxide, lavandulol, and lavandulyl acetate were included as the standard antimicrobial plant substances active against Gram-positive bacteria, Gram-negative bacteria, and yeasts. The MBC or MFC were determined by removing $20 \mu \mathrm{L}$ of the bacterial or fungal culture used for MIC determinations from each well and spotting this onto appropriate agar medium. The plates were incubated at $35^{\circ} \mathrm{C}$ for $24 \mathrm{~h}$. The lowest distillates and light oil concentrations with no visible bacterial or fungal growth were assessed as MBC or MFC, respectively. To determine the MIC, the absorbance was measured in a spectrophotometer at a wavelength of $600 \mathrm{~nm}$. The experiments were performed in triplicate. On the basis of each MIC, MBC, and MFC value, the most common representative value, i.e., mode, was presented.

\section{Conclusions}

The supercritical extracts from Lavandula angustifolia Mill. are a diverse source of phytochemicals with principal fragrance constituents. Regarding the composition of extracts obtained with high density $\mathrm{scCO}_{2}$, they mostly resembled the starting plant matter, with coumarins and fragrance molecules admixed/combined with hydrophobic components of cuticle layers covering all aerial organs of plants, i.e., flowers. The physicochemical characterizations of $\mathrm{scCO}_{2}$ extracts (L-Pl-E, L-Bg-E) obtained on a pilot scale from two sources of L. angustifolia, Poland and Bulgaria, revealed differences in cuticle layer wax compositions, which, in the case of L-Bg-E, might have included esterified phenolic fraction. This higher melting fraction most likely gave the film of the cuticle covering lavender grown in Bulgaria specific barrier properties against UV radiation and uncontrolled water loss. One of the differences between the extracts concerned the content of linalool and its derivatives. The isomers of linalool oxide (tetrahydrofuran) and terpendiol (polyhydroxylated monoterpenes), representing the group of linalool derivatives, were included in a higher content in L-Bg-E comparing to L-Pl-E. The highest activities of both extracts 
were observed against Bacillus subtilis ATCC 6633 with MIC $=0.25 \mathrm{mg} / \mathrm{mL}$ (L-Pl-E) and $\mathrm{MIC}=0.06 \mathrm{mg} / \mathrm{mL}$ (L-Bg-E).

In this research, for the first time, two procedures of molecular distillations were developed to refine the feedstocks: supercritical extracts (L-Pl-E and L-Bg-E) from L. angustifolia cultivated in Poland and Bulgaria. The variations of the extracted plant material, owing to the geographic source, made this study more challenging in terms of MD parameters having to be adjusted individually to each of the studied lavender $\mathrm{scCO}_{2}$ extracts. Each extract, $\mathrm{L}-\mathrm{Pl}-\mathrm{E}$ and L-Bg-E, was processed through five experiments, according to the influence of evaporator temperature increased stepwise from $55^{\circ} \mathrm{C}$ to $95^{\circ} \mathrm{C}$ at intervals of $10^{\circ} \mathrm{C}$. The best results and high-quality distillates (L-Pl-D4 and L-Bg-D4) were obtained at $85^{\circ} \mathrm{C}$ (EVT), and it was confirmed that the linalyl acetate content increased from $51.54 \mathrm{mg} / \mathrm{g}$ (L-Bg-E) and $89.53 \mathrm{mg} / \mathrm{g}$ (L-Pl-E) to 118.41 and $185.42 \mathrm{mg} / \mathrm{g}$, respectively, reaching an increase in its content of 2.3 and 2.1 times in both distillate streams. Once the EVT increased up to $85^{\circ} \mathrm{C}$, the contents of 1,8-cineole, linalool, terpinen-4-ol, lavandulyl acetate, lavandulol, and caryophyllene oxide doubled in the distillates streams. Those monoterpenoids, with predominating linalyl acetate and linalool, were the main active ingredients, as was studied in the extracts and distilled fractions.

Compared to the extracts, all distilled fractions with removed waxes and fatty acids by molecular distillation became valuable potential sources of lavender with antimicrobial activities against all studied Candida species. In general, $\mathrm{scCO}_{2}$ extracts are said to possess synergistic effects due to the content of the different groups of bioactive compounds. However, our studies revealed higher activities analyzed for enriched fractions (after MD) in comparison with crude extracts (without fractionation) in terms of specific pathogens. Only Bacillus subtilis was more sensitive to both extracts, rather than to the distillates and light oils.

Author Contributions: Conceptualization, A.D., Z.F. and K.T.; methodology, A.D., K.T., Z.F., P.K., G.F., M.K., E.R., A.G. and A.M.; software, Z.F., P.K., G.F. and A.G.; validation, A.D., Z.F., M.K. and K.T.; formal analysis, A.D., Z.F., K.T. and M.K.; investigation, A.D., K.T., Z.F., P.K., G.F., M.K., E.R., A.G. and A.M.; resources, E.R., A.G. and A.M.; data curation, A.D., Z.F. and K.T.; writing-original draft preparation, A.D., K.T., A.G. and A.M.; writing—review and editing, A.D., K.T., Z.F. and M.K.; visualization, A.D., K.T., Z.F. and M.K.; supervision, A.D. and K.T.; project administration, A.D. and K.T.; funding acquisition, E.R., M.K. and A.M. All authors have read and agreed to the published version of the manuscript.

Funding: This research received no external funding.

Institutional Review Board Statement: Not applicable.

Informed Consent Statement: Not applicable.

Conflicts of Interest: The authors declare no conflict of interest.

Sample Availability: Samples of the compounds are not available from the authors.

\section{References}

1. Śmigielski, K.; Raj, A.; Krosowiak, K.; Gruska, R. Chemical composition of the essential oil of Lavandula angustifolia cultivated in Poland. J. Essent. Oil Bear. Plants 2009, 12, 338-347. [CrossRef]

2. Prashar, A.; Locke, I.C.; Evans, C.S. Cytotoxicity of lavender oil and its major components to human skin cells. Cell. Proliferat. 2004, 37, 221-299. [CrossRef]

3. Denner, S.S. Lavandula angustifolia Miller, English lavender. Holist. Nurs. Pract. 2009, 23, 57-64. [CrossRef]

4. Orchard, A.; van Vuuren, S. Commercial Essential Oils as Potential Antimicrobials to Treat Skin Diseases. Review Article. Evid. Based Compl. Altern. Med. 2017, 2017, 1-92. [CrossRef]

5. Malcolm, B.J.; Tallian, K. Essential oil of lavender in anxiety disorders: Ready for prime time? Ment. Health Clin. 2017, 7, 147-155. [CrossRef]

6. Kędzia, A.; Kędzia, A.W. Effectiveness of lavender oil (Oleum Lavandulae) against yeastlike fungi from Candida species. Post. Fitoter. 2020, 21, 73-77.

7. Ali, B.; Al-Wabel, N.A.; Shams, S.; Ahamad, A.; Khan, S.A.; Anwar, F. Essential oils used in aromatherapy: A systemic review. Asian Pac. J. Trop. Biomed. F. 2015, 5, 601-611. [CrossRef] 
8. Białoń, M.; Krzyśko-Łupicka, T.; Nowakowska-Bogdan, E.; Wieczorek, P.P. Chemical Composition of Two Different Lavender Essential Oils and Their Effect on Facial Skin Microbiota. Molecules 2019, 24, 3270-3287. [CrossRef]

9. Andrei, F.; Ersilia, A.; Tulcan, C.; Dragomirescu, A. Chemical Composition and the Potential of Lavandula angustifolia L. Oil as a Skin Depigmentant. Rec. Nat. Prod. 2018, 12, 340-349. [CrossRef]

10. Wesołowska, A.; Jadczak, D.; Grzeszczuk, M. Influence of distillation time on the content and composition of essential oil isolated from lavender (Lavandula angustifolia Mill.). Herba Polonica 2010, 56, 24-36.

11. Filly, A.; Fabiano-Tixier, A.S.; Louis, C.; Fernandez, X.; Chemat, F. Water as a green solvent combined with different techniques for extraction of essential oil from lavender flowers. Comptes Rendus Chim. 2016, 19, 707-717. [CrossRef]

12. Michalak, I.; Górka, B.; Wieczorek, P.P.; Rój, E.; Lipok, J.; Łęska, B.; Messyasz, B.; Wilk, R.; Schroeder, G.; Dobrzyńska-Inger, A.; et al. Supercritical fluid extraction of algae enhances levels of biologically active compounds promoting plant growth. Eur. J. Phycol. 2016, 51, 243-252. [CrossRef]

13. Jerkovic, I.; Molnar, M.; Vidovic, S.; Vladic, J.; Jokic, S. Supercritical $\mathrm{CO}_{2}$ of Lavandula angustifolia Mill. Flowers, Coumarin and Herniarin Content. Phytochem. Anal. 2017, 28, 558-566. [CrossRef] [PubMed]

14. Nadalin, V.; Lepojevic, Z.; Ristic, M.; Vladic, J.; Nikolovski, B.; Adamovic, D. Investigation of cultivated lavender (Lavandula officinalis L.) extraction and its extracts. Chem. Ind. Chem. Eng. Q. 2014, 20, 71-86. [CrossRef]

15. Lv, G.P.; Hu, D.J.; Zhou, Y.-Q.; Zhang, Q.W.; Zhao, J.; Li, S.-P. Preparation and application of standardized typical volatile components fraction from turmeric (Curcuma longa L.) by supercritical fluid extraction and step molecular distillation. Molecules 2018, 23, 1831. [CrossRef]

16. Fang, T.; Goto, M.; Sasaki, M.; Hirose, T. Combination of supercritical $\mathrm{CO}_{2}$ and vacuum distillation for the fractionation of bergamot oil. J. Agric. Food Chem. 2004, 52, 5162-5167. [CrossRef]

17. Olivares, A.; Martínez, I.; Illanes, A. Enzyme assisted fractionation of wood sterols mixture by short path distillation. Chem. Eng. J. 2012, 191, 557-562. [CrossRef]

18. Lutisan, J.; Cvengros, J.; Micov, M. Heat and mass transfer in the evaporating film of a molecular evaporator. Chem. Eng. J. 2002, 85, 225-234. [CrossRef]

19. Cvengros, J.; Lutisan, J.; Micov, M. Feed temperature influence on the efficiency of a molecular evaporation. Chem. Eng. J. 2000, 78, 61-67. [CrossRef]

20. Tovar, L.P.; Pinto, G.M.F.; Wolf-Maciel, M.R.; Batistella, C.B.; Maciel-Filho, R. Short-Path-Distillation Process of Lemongrass Essential Oil: Physicochemical Characterization and Assessment Quality of the Distillate and the Residue Products. Ind. Eng. Chem. Res. 2011, 50, 8185-8194. [CrossRef]

21. Rossi, P.C.; Willnecker, A.A.; Berti, J.; Borgarello, A.V.; Mezza, G.N.; Pramparo, M.C. D-Limonene and Geranial Fractionation from Lemon Essential oil by Molecular Distillation. Lat. Am. Appl. Res. 2011, 41, 81-85.

22. Martinello, M.A.; Pagliero, C.L.; Allevi, C.A. Deterpenation of Orange Essential Oil by Molecular Distillation. Int. J. Eng. Trends Technol. 2015, 30, 161-165. [CrossRef]

23. Laksmono, J.A.; Augustian, E.; Adilina, I.B. Patchouli Alcohol Enrichment from Patchouli Oil using Molecular Distillation Unit. J. Tek. Ind. Pert. 2007, 17, 74-79.

24. Mezza, G.N.; Borgarello, A.V.; Daguero, J.D.; Pramparo, M.C. Obtention of Rosemary Essential Oil Concentrates by Molecular Distillation and Free Radical Scavenging Capacity Analysis. J. Food Eng. 2013, 9, 147-153. [CrossRef]

25. Olmedo, R.H.; Nepote, V.; Grosso, N.R. Antioxidant activity of fractions from oregano essential oils obtained by molecular distillation. Food Chem. 2014, 156, 212-219. [CrossRef]

26. Yia, F.; Suna, J.; Baoa, X.; Mab, B.; Suna, M. Influence of molecular distillation on antioxidant and antimicrobial activities of rose essential oils. LWT-Food Sci. Technol. 2018, 102, 310-316. [CrossRef]

27. Li, Y.; Xia, L.; Vazquez, J.F.T.; Song, S. Optimization of supercritical $\mathrm{CO}_{2}$ extraction of essential oil from Artemisia annua L. by means of response surface methodology. J. Essent. Oil Bear. Plants 2017, 20, 314-327. [CrossRef]

28. Zhong, J.-L.; Muhammad, N.; Chen, S.-Q.; Guo, L.-W.; Li, J.-S. Pilot-scale supercritical $\mathrm{CO}_{2}$ extraction coupled molecular distillation and hydrodistillation for the separation of essential oils from artemisia argyi Lévl. et Vant. Sep. Sci. Technol. 2021, 56, 3127-3135. [CrossRef]

29. Chen, F.; Wang, Z.; Zhao, G.; Liao, X.; Cai, T.; Guo, L.; Hu, X. Purification process of octacosanol extracts from rice bran wax by molecular distillation. J. Food Eng. 2007, 79, 63-68. [CrossRef]

30. Maziero, E.V.; Salles, R.B.; Tovar, L.P.; Tanabe, E.H.; Bertuol, D.A. Fractionation of polyethylene wax by pilot-scale molecular distillation: New insights on process development. Chem. Eng. Res. Design. 2019, 152, 201-215. [CrossRef]

31. Tyśkiewicz, K.; Konkol, M.; Rój, E. Supercritical carbon dioxide $\left(\mathrm{scCO}_{2}\right)$ extraction of phenolic compounds from lavender (Lavandula angustifolia) flowers: A box-behnken experimental optimization. Molecules. 2019, 24, 3354-3369. [CrossRef] [PubMed]

32. Sovova, H.; Stateva, R.P. New Approach to Modelling Supercritical CO2 Extraction of Cuticular Waxes: Interplay between Solubility and Kinetics. Ind. Eng. Chem. Res. 2015, 54, 4861-4870. [CrossRef]

33. Reverchon, E. Supercritical fluid extraction and fractionation of essential oils and related products. J. Supercrit. Fluid. 1997, 10, 1-37. [CrossRef]

34. Reverchon, E.; Della Porta, G.; Senatore, F. Supercritical $\mathrm{CO}_{2}$ extraction and fractionation of lavender essential Oil. J. Agric. Food Chem. 1995, 43, 1654-1658. [CrossRef] 
35. Da Porto, C.; Decorti, D.; Kikic, I. Flavour compounds of Lavandula angustifolia L. to use in food manufacturing: Comparison of three different extraction methods. Food Chem. 2009, 112, 1072-1078. [CrossRef]

36. Mallavarapu, G.R.; Mehta, V.K.; Sastry, K.P.; Krishnan, R.; Ramesh, S.; Kumar, S. Composition of lavender oils produced in Kashmir and Kodaikanal. J. Med. Arom. Plant Sci. 2000, 22, 768-770.

37. Guo, X.; Wang, P. Aroma characteristics of lavender extract and essential oil from Lavandula angustifolia Mill. Molecules 2020, 25, 5541-5555. [CrossRef]

38. Duskova, E.; Dusek, K.; Indrak, P.; Smekalova, K. Postharvest changes in essential oil content and quality of lavender flowers. Ind. Crop. Prod. 2016, 79, 225-231. [CrossRef]

39. Ozek, T.; Tabanca, N.; Demirci, F.; Wedge, D.E.; Husnu Can Baser, K. Enantiomeric Distribution of Some Linalool Containing Essential Oils and Their Biological Activities. Rec. Nat. Prod. 2010, 4, 180-192.

40. Jerkovic, J.; Kuś, P.M. Terpenes in honey: Occurrence, origin and their role as chemical biomarkers. RSC Adv. 2014, 4, 31710-31728. [CrossRef]

41. Alissandrakis, E.; Tarantilis, P.A.; Harizanis, P.C.; Polissiou, M. Aroma investigation of unifloral Greek citrus honey using solid-phase microextraction coupled to gas chromatographic-Mass spectrometric analysis. Food Chem. 2007, 100, 396-404. [CrossRef]

42. Chen, X.; Yauk, Y.-K.; Nieuwenhuizen, N.J.; Matich, A.J.; Wang, M.Y.; Perez, R.L.; Atkinson, R.G.; Beuning, L.L. Characterisation of an (S)-linalool synthase from kiwifruit (Actinidia arguta) that catalyses the first committed step in the production of floral lilac compounds. Funct. Plant Biol. 2010, 37, 232-243. [CrossRef]

43. Lesage-Meessen, L.; Bou, M.; Sigoillot, J.-C.; Faulds, C.B.; Lomascolo, A. Essential oils and distilled straws of lavender and lavandin: A review of current use and potential application in white biotechnology. Appl. Microbiol. Biotechnol. 2015, 99, 3375-3385. [CrossRef] [PubMed]

44. Cavanagh, H.M.A.; Wilkinson, J.M. Biological activities of lavender essential oil. J. Phytochem. Res. 2002, 16, 301-308. [CrossRef] [PubMed]

45. Lis-Balchin, M.; Hart, S. Studies on the mode of action of the essential oil of lavender (Lavandula angustifolia P. Miller). Phytother Res. 1999, 13, 540-542. [CrossRef]

46. Fidyt, K.; Fiedorowicz, A.; Strządała, L.; Szumny, A. Review $\beta$-caryophyllene and $\beta$-caryophyllene oxide-Natural compounds of anticancer and analgesic properties. Cancer Med. 2016, 5, 3007-3017. [CrossRef]

47. Ngamprasertish, S.; Menwa, J.; Sawangkeaw, R. Caryophyllene oxide extraction from lemon basil (Ocimum citriodorum Vis.) straw by hydrodistillation and supercritical $\mathrm{CO}_{2}$. J. Supercrit. Fluid. 2018, 138, 1-6. [CrossRef]

48. Najmanova, I.; Dosedel, M.; Hrdina, R.; Anzenbacher, P.; Filipsý, T.; Říha, M.; Mladenka, P. Cardiovascular effects of coumarins besides their antioxidant activity. Curr. Top. Med. Chem. 2015, 15, 830-849. [CrossRef]

49. Ruguo, Z.; Hua, Z.; Hong, Z.; Ying, F.; Kun, L.; Wenwen, Z. Thermal analysis of four insect waxes based on differential scanning calorimetry (DSC). Procedia Eng. 2011, 18, 101-106. [CrossRef]

50. Donhowe, G.; Fennema, O. Water vapor and oxygen permeability of wax films. JAOCS 1993, 70, 867-873. [CrossRef]

51. Barthlott, W.; Mail, M.; Bhushan, B.; Koch, K. Plant surfaces: Structures and functions for biomimetic innovations, Review. Nano-Micro Lett. 2017, 9, 1-40. [CrossRef]

52. Charumanee, S.; Yotsawimonwat, S.; Sirisa-ard, P.; Pholsongkram, K. Characterization and chemical composition of epicuticular wax from banana leaves grown in Northern Thailand. Songklanakarin J. Sci. Technol. 2017, 39, 509-516.

53. Freitas, C.A.S.; Vieira, I.G.P.; Sousa, P.H.M.; Muniz, C.R.; da Costa Gonzaga, M.L.; Guedes, M.I.F. Carnauba wax pmethoxycinnamic diesters: Characterization, antioxidant activity and simulated gastrointestinal digestion followed by in vitro bioaccessibility. Food Chem. 2016, 196, 1293-1300. [CrossRef] [PubMed]

54. Panteli, E.; Saratsioti, P.; Stamatis, H.; Voutsas, E. Solubilities of cinnamic acid esters in organic solvents. J. Chem. Eng. Data 2010, 55, 745-749. [CrossRef]

55. Najibullah, S.N.M.; Ahamad, J.; Aldahish, A.A.; Sultana, S.; Sultana, S. Chemical Characterization and $\alpha$-Glucosidase Inhibitory Activity of Essential Oil of Lavandula angustifolia Flowers. J. Essent. Oil Bear. Plants 2021, 24, 431-438. [CrossRef]

56. Tankeu, S.Y.; Vermaak, I.; Kamatou, G.P.P.; Viljoen, A.M. Vibrational spectroscopy and chemimetric modelling: An economical and robust quality control method for lavender oil. Ind. Crops Prod. 2014, 59, 234-240. [CrossRef]

57. Agatonovic-Kustrin, S.; Ristivojevic, P.; Gegechkori, V.; Litvinova, T.M.; Morton, D.W. Essential oil quality and purity evaluation via ft-ir spectroscopy and pattern recognition techniques. Appl. Sci. 2020, 10, 7294-7305. [CrossRef]

58. Nelson, R.R.S. In vitro activities of five plant essential oils against methicillin-resistant Staphylococcus aureus and vancomycinresistant Enterococcus faecium. J. Antimicrob. Chemother. 1997, 40, 305-306. [CrossRef]

59. Lis-Balchin, M.; Deans, S.G.; Eaglesham, E. Relationship between bioactivity and chemical composition of commercial essential oils. Flavour Fragr. J. 1998, 13, 98-104. [CrossRef]

60. Shellie, R.; Mondello, L.; Marriott, P.; Dugo, G. Characterization of lavender essential oils by using gas chromatographymass spectrometry with correlation of linear retention indices and comparison with comprehensive two-dimensional gas chromatography. J. Chromatogr. A. 2002, 970, 225-234. [CrossRef]

61. Predoi, D.; Iconaru, S.L.; Buton, N.; Badea, M.L.; Marutescu, L. Antimicrobial activity of new materials based on lavender and brasil essential oils and hydroxyapatite. Nanomaterials 2018, 8, 291. [CrossRef] [PubMed] 
62. Pankey, G.A.; Sabath, L.D. Clinical relevance of bacteriostatic versus bactericidal mechanisms of action in the treatment of gram-positive bacterial infections. Clin. Infect. Dis. 2004, 38, 864-870. [CrossRef] [PubMed]

63. Moussi Imane, M.; Houda, F.; Said Amal, A.H.; Kaotar, N.; Mohammed, T.; Imane, R.; Farid, H. Phytochemical composition and antibacterial activity of Moroccan Lavandula angustifolia Mill. J. Essent. Oil Bear. Plants 2017, 20, 1074-1082. [CrossRef]

64. Ciocarlan, A.; Lupascu, L.; Aricu, A.; Dragalin, I.; Popescu, V.; Geana, E.-I.; Ionete, R.E.; Vornicu, N.; Duliu, O.G.; Hristozova, G.; et al. Chemical composition and assessment of antimicrobial activity of lavender essential oil and some by-products. Plants 2021, 10, 1829. [CrossRef] [PubMed]

65. Caprari, C.; Fantasma, F.; Divino, F.; Bucci, A.; Iorizzi, M.; Naclerio, G.; Ranalli, G.; Saviano, G. Chemical Profile, In vitro biological activity and comparisonof essential oils from fresh and dried flowers of Lavandula angustifolia L. Molecules. 2021, 26, 5317-5337. [CrossRef]

66. Peana, A.T.; D'Aquila, P.S.; Panin, F.; Serra, G.; Pippia, P.; Moretti, M.D.L. Anti-inflammatory activity of linalool and linalyl acetate constituents of essential oils. Phytomedicine 2002, 9, 721-726. [CrossRef]

67. Trombetta, D.; Castelli, F.; Sarpietro, M.G.; Venuti, V.; Cristani, M.; Daniele, C.; Saija, A.; Mazzani, G.; Bisignano, G. Mechanism of antibacterial action of three monoterpenes. Antimicrob. Agents Chemother. 2005, 49, 2474-2478. [CrossRef]

68. Liu, X.; Cai, J.; Chen, H.; Zhong, Q.; Hou, Y.; Chen, W.; Chen, W. Antibacetrial activity and mechanism of linalool against Pseudomonas aeruginosa. Microb. Pathog. 2020, 141, 103980. [CrossRef]

69. D'Auria, F.D.; Tecca, M.; Strippoli, V.; Salvatore, G.; Battinelli, L.; Mazzanti, G. Antifungal activity of Lavandula angustifolia essential oil against Candida albicans and mycelial form. Med. Mycol. 2005, 43, 391-396. [CrossRef]

70. Babu, G.D.K.; Sharma, A.; Singh, B. Volatile composition of Lavandula angustifolia produced by different extraction techniques. J. Ess. Oil Res. 2016, 28, 489-500. [CrossRef]

71. Tardugno, R.; Serio, A.; Pellati, F.; D’Amato, S.; Chaves López, C.; Bellardi, M.G.; Di Vito, M.; Savini, V.; Paparella, A.; Benvenuti, S. Lavandula $x$ intermedia and Lavandula angustifolia essential oils: Phytochemical composition and antimicrobial activity against foodborne pathogens. Nat. Prod. Res. 2019, 33, 3330-3335. [CrossRef] [PubMed]

72. Śmigielski, K.B.; Prusinowska, R.; Krosowiak, K.; Sikora, M. Comparison of qualitative and quantitative chemical composition of hydrolate and essential oils of lavender (Lavandula angustifolia). J. Essent. Oil Res. 2013, 25, 291-299. [CrossRef]

73. Aćimović, M.G.; Tešević, V.V.; Smiljanić, K.T.; Cvetković, M.T.; Stanković, J.M.; Kiprovski, B.M.; Sikora, V.S. Hydrolates-byproducts of essential oil distillation: Chemical composition, biological activity and potential uses. Adv. Mater. Technol. 2020, 9 , 54-70. [CrossRef]

74. Garzoli, S.; Laghezza Masci, V.; Franceschi, S.; Tiezzi, A.; Giacomello, P.; Ovidi, E. Headspace/GC-MS Analysis and investigation of antibacterial, antioxidant and cytotoxic activity of essential oils and hydrolates from Rosmarinus officinalis L. and Lavandula angustifolia Miller. Foods 2021, 10, 1768. [CrossRef] [PubMed]

75. European Committee for Antimicrobial Susceptibility Testing (EUCAST) of the European Society of Clinical Microbiology and Infectious Diseases (ESCMID). Determination of minimum inhibitory concentrations (MICs) of antibacterial agents by broth dilution. EUCAST Discussion Document E.Dis 5.1; The European Committee on Antimicrobial Susceptibility Testing. Clin. Microbiol. Inf. Dis. 2003, 9, 1-7. 